\title{
EL PASAJE DEL PSEUDO-FREDEGARIO SOBRE EL DUX FRANCIO DE CANTABRIA Y OTROS INDICIOS DE NATURALEZA TEXTUAL Y ONOMÁSTICA SOBRE PRESENCIA FRANCA TARDOANTIGUA AL SUR DE LOS PIRINEOS
}

\author{
POR \\ K. Larrañaga Elorza \\ Universidad del País Vasco (Área de Historia Antigua)
}

\begin{abstract}
RESUMEN
Los sorprendentes hallazgos de Aldaieta (Álava) y Buzaga (Navarra), que han revelado la presencia - al Sur de la cadena pirenaica- - de comunidades humanas de - al parecer - fuerte componente militar y con elementos de civilización material a referir inequívocamente a un mundo de influencias norpirenaico (del área aquitano-novempopulana, más concretamente), han hecho que el autor vuelva a preguntarse sobre la credibilidad de un célebre y discutido texto - el del Pseudo-Fredegario - , que hablaba de un enclave cispirenaico que pagaba tributos a los reyes francos allá por los finales del siglo Vi y/o comienzos del VII. Un detenido examen de la cuestión lleva al autor a pensar que, a la luz de los referidos hallazgos de orden arqueológico, lo que en dicho pasaje resultaba de más chocante y llamativo se vuelve ahora menos incongruente o inverosímil, y que otra serie de indicios de naturaleza textual y onomástica, que antes venían siendo preteridos a falta de referentes hermenéuticos minimamente aceptables, cobran hoy, a la luz de esos mismos hallazgos, una nueva dimensión interpretativa, enigmática y turbadora.
\end{abstract}

\section{SUMMARY}

The surprising finds at Aldaieta (Alava) and Buzaga (Navarre), that had revealed the presence - in the south of the Pyrenean range - of human comunities of - apparently - a strong military component and with elements of material civilization referring without doubt to a world with north-pirenean influences, have made the author wonder about the credibility of the famous and controversial text - that of Pseudo-Fredegario- which talked about a Cispyrenean enclave that paid taxes to the Merovingians Kings at around the end of the sixth century and/or beginning of the seventh century. A 
careful examination of the subject makes the author think that, in the light of the mentioned archaeological finds, which in the said text war more schocking and gaudy becomes now less incongruent or improbable, and that other set of onomastical and textual hints, that were before left out due to the lack of hermeneutical references minimally acceptable, becomes nowadays, in the light of these same finds, of a new interpretative dimension, enigmatic and upsetting.

Auténtica crux interpretum desde tiempo atrás, la frase del Pseudo-Fredegario (PF, en adelante) ', relativa a la actividad bélica de Sisebuto y al duque de Cantabria Francio, no ha dejado hasta hoy mismo de intrigar a los estudiosos que se han interesado por las vicisitudes de las partes norteñas de la Península Ibérica durante la Antigüedad Tardia ${ }^{2}$. Sólo que, por su escritura o latin peculiar - no más peculiar, en todo caso, que el de otros pasajes del mismo autor-y tratándose, por otro lado, como se trata de algo así como un hapax legómenon - una noticia o referencia sin paralelos o contrastes coetáneos conocidos, la que a mayor abundamiento choca frontalmente con ciertos clichés historiográficos comúnmente aceptados-, ha sido objeto de enjuiciamientos harto dispares. No entra en nuestros propósitos hacer aquí y ahora la historia de las interpretaciones que se han dado de tan famoso y enigmático pasaje, y menos formular por nuestra parte una nueva, que pudiera estimarse superadora de las precedentes. Digamos a lo sumo, para abreviar, respecto a lo primero, que los más de los autores - sobre todo, los peninsulares ${ }^{3}$, pero también los de otras procedencias ${ }^{4}$ - han tendido a restar credibilidad al testimonio del PF, estimándolo fabuloso y de carácter épico. Con la salvedad de que tampoco han faltado quienes lo han valorado menos negativamente, $y$ han pasado a formular hipótesis sobre el tiempo y el modo en que habría surgido ese supuesto enclave de dominio franco al Sur de los Pirineos ${ }^{5}$. Pero, como hemos dicho, el objeto de nuestra colaboración no es el de hacer

1 Sobre la problemática de los textos que se recubren bajo el nombre genérico de Crónicas de Fredegario, v. estudio preliminar de B. Krusch a su edición de las mismas en MGH, SRM, II, Hannover 1888, pp. 1-93, particularmente pp. 1-9. V. item J. Wallace-Hadrill: The Fourth Book of Fredegar Chronicle [con traducción del texto al inglés], London 1960.

2 Cfr., entre otros, J-.F. Bladé: La Vasconie cispyrénéenne jusqu'à la mort de Dagobert, Le-Puy 1891, pp. 67-74; J. González Echegaray: La "nota de Cantabria» del códice emilianense 39 y las citas medievales de Cantabria, en "Altamira» 40, 1976-1977, 61-94, part. 75s; M. Rouche: L'Aquitaine des Wisigoths aux Arabes (418-781). Naissance d'une région, Paris 1979, p. 506, nota 24, x; A. Besga: La situación politica de los pueblos del Norte de España en la época visigoda. Bilbao 1983, pp. 17-21 y 60-77, en los que podrán encontrarse otras referencias de autores - antiguos y modernos - que se han ocupade del tema.

${ }^{3}$ V., por ej., J. Moret: Anales del Reyno de Navarra, v. I, Pamplona 1766 (reimpr. facsimil, Bilbao 1969), pp. 89 y ss; M. Risco: La Vasconia (=España Sagrada, t. 32), Madrid 2. ed. 1878, pp. 324-33; A. Besga Marroquin: o. c., pp. 64-68.

4 Así, por ej., J.-F. Bladé: o. c., ibid. y part. p. 74; J. de Jaurgain: La Vasconie: étude historique et critique sur les origines du royaume de Navarre..., 2tt., Pau 1898-1902, t. I, pp. 35 y ss; M. Rouche: $o . c .$, ibid., etc., en quienes se hallarán más referencias a autores antiguos.

5 Así, por ej., G. Balparda: Historia critica de Vizcaya y de sus fueros, 2 vv., Bilbao 1974, v. I, pp. 120 y 128-130; A. Barbero-M. Vigil: Sobre los origenes sociales de la Reconquista, Barcelona 1974, pp. 59 y 87. El mismo C. Sánchez Albornoz - y no obstante sustanciales reservas frente al texto del cronista franco - no le niega alguna verosimilitud (v. su Alfonso III y el particularismo castellano [1950], en Id.: Vascos y navarros en su primera historia [1975], Madrid 1976, p. 189, nn. 54 y 55; Id.: Observaciones a unas páginas sobre el inicio de la Reconquista, en "Cuadernos de Historia de España», 47-48, 1968, p. 348). Algo por el estilo cabe decir de J. Orlandis (v. Historia de España. Época visigoda [409-711], Madrid 1987, p. 133; Historia del reino visigodo español, Madrid 1988, pp. 105s.) 
la reseña de las interpretaciones dadas al texto del PF. Por el contrario, nuestro interés se ciñe a llamar la atención sobre el hecho de que, a la luz de ciertos hallazgos de orden arqueológico que vienen produciéndose en los últimos años, lo que en dicho pasaje resultaba de más chocante y llamativo parece volverse ahora un poco menos incongruente o inverosimil, y que, a la luz de esos mismos hallazgos, otra serie de indicios de naturaleza textual y onomástica, que venían siendo olvidados o preteridos a falta de referentes hermenéuticos minimamente aceptables, cobran hoy una nueva dimensión interpretativa, enigmática y turbadora.

Los hallazgos de orden arqueológico, a que nos estamos refiriendo, son los que, localizados básicamente en Aldaieta (Nanclares de Gamboa, Álava) y Buzaga (valle de Elorz, Navarra), son objeto de los precisos análisis de A. Azkárate en el interesantísimo trabajo que acompaña a estas lineas ${ }^{h}$. Nosotros, por nuestra parte, nos limitaremos a reunir y comentar todos aquellos pasajes documentales e indicios onomásticos que, a la luz de lo que sugieren esos hallazgos arqueológicos, podrian ser susceptibles de una interpretación que avalase el viejo testimonio del PF o, en todo caso, hiciese menos incongruente la especie de ámbitos de dominación franca precarolingia al Sur de los Pirineos.

Una observación fundamental antes de pasar adelante. $\mathrm{Y}$ es la de que, cuando en el curso del trabajo se habla de eventuales episodios de dominación franca al sur de la cadena pirenaica, el término franco no ha de ser entendido por necesidad en sentido estricto - cual si los protagonistas de los mismos hubieran pertenecido al grupo étnico de los Franci--, sino en uno más amplio, comprensivo de cualquier instancia de poder norpirenaica - del área novempopulano-aquitana, por ej.—, que, moviéndose en la esfera de influencia — más o menos real, más o menos teóricade los dinastas francos, pudieron eventualmente protagonizar hechos de dominación al sur de la cadena, guardando en mayor o menor grado las formas de subordinación jerárquica respecto de aquéllos. Y, al hablar así, está claro que no excluimos soluciones como las que apunta en su trabajo A. Azkárate, que nos remitirian a un mundo aquitano que las fuentes cronísticas del tiempo se empeñan en confundir cada día más con el de una Vasconia sobredimensionada?, mundo - éste- que, por otro lado y según se sabe, constituyó durante años la reserva más importante de las fuerzas de choque de que se valió la clase dirigente aquitana en su secular enfrentamiento contra los amos del Norte.

\section{EL TEXTO DEL PSEUDO-FREDEGARIO}

Pero, antes de entrar en el debate, urge que analicemos con algún detenimiento el discutido pasaje del PF.

Suena así en la edición de B. Krusch ${ }^{8}$ :

- V., además, A. Azkárate: Algunas consideraciones sobre la arqueología de época germánica en Euskal Herria, en «Munibe. Antropología-Arqueologia» 42, 1990, 345-355; ID.: El eremitismo de época visigótica. Testimonios arqueológicos, en IV Seminario sobre el monacato (= «Codex Aquilarensis» [Aguilar de Campoo] 5, 1991), pp. 141-179.

7 V. en este punto la parte introductoria de nuestro trabajo Euskal Herria Antzinate Berantiarrean eta Lehen Ertaroan (VI-X, mendeak), Bilbao 1993, en que se hallarán algunas referencias documentales y bibliográficas (la versión castellana de la obra, con el título de Euskal Herria en la Tarda Antigüedad y en el primer Medioevo [ss. VI-X], verá la luz en breve).

${ }^{8}$ IV, 33 (ed. de B. Krusch, p. 133). 
Eo anno, mortuo Betterico. Sisehodus Spaniae successit in regno, vir sapiens et in totam Spaniam laudahelis valde, pietate plenissemus. Nam et adversus manum publecam romanam fortiter demicavit: prouinciam Cantabriam Gothorum regno subaegit, quam aliquando Franci possederant. Dux Francio nomen, qui Cantabriam in tempore Francorum egerat, tributa Francorum regibus multo tempore impleuerat; sed cum parte imperiae fuerat Cantabria reuocata, a Gothis, ut super legetur, preoccupatur, et plures ciuitates ab imperio Romano Sisebodus litore maris abstulit et usque fundamentum destruxit. [...] Confirmatum est regnum Gothorum in Spaniam per mare litora usque Paereneos montes.

Texto que, traducido al castellano, podría sonar as ${ }^{\text {": }}$

«En ese año [el XII del reinado de Teodorico II, es decir, el $607 \mathrm{~d}$. de C.], habiendo muerto Witerico, le sucedió Sisebuto en el reino de España, varón sabio y muy encomiado en toda España y colmado de piedad. Y es que combatió ardorosamente a la república romana, y sometió al reino de los Godos la provincia de Cantabria, la que por algún tiempo poseyeron los Francos. Un dux, de nombre Francio, que en los dias de los Francos había administrado Cantabria, pagó por mucho tiempo tributos a los reyes francos; mas como Cantabria fuese declarada de nuevo parte del Imperio, fue ocupada, según se dice arriba, por los Godos, y Sisebuto arrebató muchas ciudades al imperio romano en la costa y las destruyó hasta los cimientos. [...] En España se robusteció el reino godo por la ribera del mar hasta los montes Pirineos»".

Dejando ahora de lado cuestiones como la de que el cronista ignora el reinado de Gundemaro (610-612) y parece aun adelantar unos años la desaparición de Witerico (octubre de 610), hay varias cosas - por lo que hace particularmente a nuestro objeto - que a una simple lectura llaman la atención en este pasaje. Una primera es la especie de que una provincia llamada Cantabria estuvo sometida por algún tiempo a los Francos; de hecho $-\mathrm{y}$ puesto a singularizar situaciones-, el cronista sabe de un dux, llamado Francio, que «durante mucho tiempo pagó tributos a los reyes» merovingios. Otro dato importante que se desprende del texto es el de que Sisebuto consiguió al cabo anexionarse dicha provincia - un Sisebuto que, por otro lado, es presentado bajo una luz favorabilísima, detalle no irrelevante, viniendo como vienen los elogios de la pluma de un escritor franco- .

Junto a esas referencias que interesa particularmente resaltar, hay otras -más embrolladas - que tienen que ver con las relaciones del monarca godo con los Romanos. De hecho, se alude dos -o quizá tres - veces a esas acciones de Sisebuto contra la res publica. De tales referencias una - la primera - no reviste dificultad interpretativa particular, sabiendo como

" Hemos de avisar al lector que nuestra versión - bastante próxima a la de un M. Risco (o. c., p. 323), y sobre todo, a la de J.-F. Bladé (o. c., p. 67) - dista no poco de otras que hemos visto por ahí, que no han acabado de convencernos. Es probable que tampoco ésta convenza a más de uno; pero, en todo caso, nos ha parecido más ajustada al texto del PF que otras: v., por ej., la de J. González Echegaray (o. c., p. 75, nota 44), o de la A. Besga (o. c., pp. 60s), quien en el punto más embrollado sigue a la letra la de G. Echegaray. Hemos de advertir aqui que el texto latino que maneja éste - transcrito, según se dice, de Fontes Hispaniae Antiquae (IX, p. 244) - suena "semper legetur", siendo así que A. Besga, remitiéndose a esa misma edición, lee «super legetur», como lo hace B. Krusch cuyo texto, por otro lado, sirvió de base a R. Grosse para su edic. de Fontes Hispaniae Antiquae. El detalle no carece de importancia, porque es ese «semper» - en lugar de «super»- lo que justificaría de alguna forma y en parte el giro interpretativo que se permite G. Echegaray, y que, copiándolo, hace también suyo A. Besga, aunque en presencia de un texto latino ligeramente diferente. 
sabemos que uno de los frentes de lucha del Estado godo venia estando desde los dias de Atanagildo en la provincia bizantina del área litoral del Sudeste: Sisebuto - viene a decir el texto comentado-adversus manum publecam fortiter demicavit. Pero el cronista franco vuelve a referirse al Imperio - y en términos de harto más problemática comprensión - al tratar de la ocupación de Cantabria por los Visigodos: cum parte imperiae fuerat Cantabria revocata, a Gothis, ut super legetur, preoccupatur. Y termina el texto del borgonón haciendo que al relato de esa campaña en el Norte peninsular siga - separado con una simple coma, y enlazado con un et- lo que parece ser el relato de otras acciones de Sisebuto contra los bizantinos, pero en el área litoral del Sudeste: et plures civitates ab imperio Romano Sisebodus litore maris abstulit.

Digamos, para empezar, que las palabras de lo que dentro del texto hemos distinguido como segunda referencia al Imperio han dado pie a toda suerte de lecturas e interpretaciones. Los hay quienes han interpretado la frase sed cum parte imperiae fuerat Cantabria revocata cual si en ella se hablase de cuando la Cantabria fue segregada del Imperio, pero retrotrayendo - según parece - el tiempo en que se consumó esa segregación a los dias ya lejanos de la descomposición del Imperio romano de Occidente ${ }^{10}$. Bajo la pluma de otros el término revocata se cobra un sentido del todo diferente. Así, por ej., J.-F. Bladé — en un intento de traducción literal del texto cronístico- habla de cuando la provincia de Cantabria volvió nuevamente a formar parte del Imperio " - es decir, según entendemos, después de un cierto tiempo durante el que, por lo visto, dejó de pertenecerle-. A esa interpretación se aviene también J. de Jaurgain quien, manejando el texto del PF, reproduce casi a la letra la traducción del erudito gascón $^{12}$. Y volviendo atrás, vemos que se expresó de manera no muy diferente M. Risco que habla también, traduciendo de forma más o menos literal este pasaje, de una tierra de Cantabria que, tras haberla gobernado el duque Francio, «fue después conquistada, y recobrada por el Imperio, de quien fue poseída hasta que la ocuparon los Godos, apoderándose de ella Sisebodo" ${ }^{13}$. Otros, en fin, tientan fórmulas menos trilladas de interpretación y, si se nos apura, más en línea con lo que se entiende debió de suceder, pero ello a costa de forzar no poco la literalidad del texto pseudo-fredegariano. Asi, por ej., J. González Echegaray ofrece la siguiente traducción del pasaje comentado: «[...] pero al ser incorporada Cantabria a los Godos, siendo parte del Imperio, según siempre ha constado, toma sus precauciones y entonces Sisebuto arrebató [etc. $)^{14}{ }^{14}$. Traducción que en este punto concreto hace literalmente suya también A. Besga Marroquin ${ }^{15}$, la que, empero, no dejará presumiblemente de suscitar obje-

${ }^{10}$ V., por ej., G. Balparda: $o$. c., v. I, p. 128, quien ofrece esta traducción del pasaje: «Pero cuando la Cantabria fue segregada del Imperio, los Godos, como arriba se dice, la ocuparon y Sisebodo quitó [etc.]». Conviene, empero, anotar aqui que ese giro interpretativo le es facilitado o sugerido a Balparda por una versión un tanto corregida del texto latino, versión que, por ej., introduce la preposición $a$ ( $a$ parte Imperii fuerat Cantabria revocata) después del Sed cum.

"Se expresa así para el pasaje comentado, dentro de lo que - como dicho- avanza como intento de traducción literal del texto cronístico: «[...] mais cette province étant revenue à l'Empire, les Goths s'en emparèrent, et Sisebuth [etc.]» (o. c., p. 67).

12 O. c., I, p. 36.

${ }^{13}$ O. c., p. 325 . Se entiende que se trata al caso de lo que, según interpreta $M$. Risco, dice en su embrollado texto el cronista; no, de lo que piensa al respecto el continuador de la España Sagrada.

14 O. c., p. 75 , nota 44.

is $O$. c., p. 61 . 
ciones a más de uno, y no sólo por lo que más arriba deciamos en nota ${ }^{16}$ sobre el cambio - por descuido- de super en semper en el texto latino que maneja González Echegaray.

Pero, como quiera que el esclarecimiento de las vicisitudes politicas que afectaron a la "provincia de Cantabria» durante la Antigüedad Tardia interesa sólo aqui en la medida en que las mismas tienen que ver con el objeto especifico de nuestro trabajo, vamos a dejar de lado por ahora cuanto se refiere al objeto de esas supuestas relaciones de la provincia con el Imperio en los tiempos visigóticos, y a centrarnos, por el contrario, en el análisis de las razones que han determinado el escepticismo o las reticencias de la mayoria de los autores frente a las otras dos informaciones que hemos destacado del texto del PF.

\section{LAS RAZONES DE LOS ESCÉPTICOS Y RETICENTES}

Entre las razones que explican el escepticismo de los autores frente al hapax del PF, una principal deriva del hecho de que en los textos tardoantiguos no se registra una sola referencia - a excepción del comentado del cronista borgoñón-que explicita o implícitamente aluda a hechos de dominación o asentamiento franco al Sur de los Pirineos. Como escribe M. Risco, «ningún escritor antiguo, nacional o extranjero, hace memoria de lo que refiere Fredegario» ${ }^{17}$, lo que en su opinión arguye a las claras el carácter «muy fabuloso» de todo el capitulo». Abundando en la especie del aire legendario o épico, de que se resintiria en su opinión el relato del PF en este punto, B. Krusch subraya el detalle de que se asocie al nombre de un Francio -homónimo de aquel mítico fundador de la estirpe, del que, según la misma crónica ${ }^{18}$, derivaria el prestigioso étnico Franci - la titularidad de ese ducado de Cantabria sujeta al dominio merovingio ${ }^{19}$.

Por otro lado, y para dejar más en evidencia aún la inverosimilitud de la especie — recogida por el cronista franco - de un ámbito de dominación merovingia al sur de la cadena pirenaica, los autores han venido insistiendo en el hecho de que, en las escasísimas ocasiones en que los textos coetáneos hablan de acciones francas episódicas al Sur de la cadena, se presentan éstas de naturaleza tal, que parecería impropio al caso estimar el que de ellas se hubieran podido seguir hechos más o menos importantes de dominación.

De tales acciones francas al Sur de los Pirineos, la que, a la luz de esos mismos textos, se ofreceria, según estos autores ${ }^{20}$, con unas mayores trazas de haber podido estar en el origen de un hipotético episodio de ocupación, se contaria la marcha que en el año 542 protagonizaron Childeberto y Clotario sobre la Tarraconense. No han faltado de hecho autores que, dando por buena la información del PF sobre el duque Francio, han visto en dicha expedición el origen

16 V. supra, nota 9.

17 O. c., pp. 330 y 331 , respectivamente, las palabras entrecomilladas.

ix Fredegario II, 5 y III, 22 (ed. de B. Krusch, pp. 46 y 93, respectivamente). V. asimismo S. Isidoro en sus Etym. (IX, 2, 101): "Francia quodam propio duce vocari putantur».

${ }_{14}$ V. su edición de las Crónicas de Fredegario en $M G H, S R M$, II, p. 133, nota 6. En el estudio preliminar a la edición del texto, y al hablar de las fuentes de que echan mano Fredegario y sus continuadores, no deja de subrayar la afición que muestran por los relatos o tradiciones que se transmitian oralmente entre el pueblo («Märchen» en alemán); no asi por las fábulas de tipo hagiográfico, las que se relegan por lo común al olvido.

${ }^{20} \mathrm{~V}$. por ej., cómo se expresa M. Risco: o. c., p. 324. 
del supuesto ducado merovingio de Cantabria ${ }^{21}$. Sin embargo, lo que las fuentes en su conjunto revelan sobre las circunstancias de esa expedición estaria muy lejos de abonar, según opinan los escépticos o reticentes, una tal interpretación. Contamos, como es sabido, con tres referencias esenciales sobre dicho evento - dos de origen peninsular y otra de allende el Pirineo-: el breve apunte de la asi llamada Chronica Caesaraugustana 22 , el relato - algo posterior y más desarrollado - de Gregorio de Tours ${ }^{23}, \mathrm{y}$, por último, la versión que ofrece San Isidoro en su Historia Gothorum ${ }^{24}$. Ahora bien, la impresión que para una mayoría de autores - modernos, sobre todo- se desprende de colegir y contrastar estas tres fuentes de información, es la de que, muy lejos de lo que afirmaron el cardenal Baronio ${ }^{25} \mathrm{y}$ otros, la expedición de «los cinco reyes» se saldó con muy otra cosa que una victoria total, que habría dado pie a supuestos hechos duraderos de dominación en el área de la Tarraconense ${ }^{26}$. Y este fracaso - o semifracaso, según por dónde se lo mire - no vendría a ser sino «la primera de una serie de derrotas ininterrumpidas» - subraya un moderno estudioso francés ${ }^{27}$ - que sufririan las armas francas frente a los Visigodos en los decenios siguientes. Sólo que, como es sabido, esos sucesivos enfrentamientos entre el aparato de poder godo y los Francos no tendrán ya como escenario la provincia Tarraconense, sino - según dan a entender las fuentes en que se hace relación de los mismos - allende los Pirineos, en la más lejana provincia de Septimania.

Hay, empero, memoria de otra acción armada de los Francos, que, por las trazas ${ }^{2 x}$, tiene lugar a este lado del Pirineo: la expedición del duque Bladastes a Vasconia en el año 581. Pero se trataría esta vez - si nos atenemos a la literalidad del texto - de una acción armada que no

21 Asi, por ej., P. de la Marca (Histoire de Béarn, cap. XXIII [ed. de V. Dubarat, 2 t., Pau 18941912 , t. I, p]), contra quien arremete M. Risco (o. c., 323 y $331-333$ ).

22 Adann. 542 (ed. de Th. Mommsen en $M G H, A A ., 11^{2}$, Berlín 1894, p. 223). Es probable que haya que entender referido a este suceso un breve pasaje de Jordanes sobre el rey Theudis: Francorum insidiosam calumniam de Spaniis pepulit (De origine actibusque Getarum, 58, 302 [ed. de Th. Mommsen en $M G H, A A, V^{\prime}$, Berlín 1882, pp. 135s]). De ser eso así, tendríamos otro testimonio más $-\mathrm{y}$ rigurosamente coetáneo - sobre los hechos en cuestión, un testimonio que, por otra parte, avalaria en su enorme concisión la versión isidoriana de los mismos.

${ }^{23}$ Hist., III, 29.

24 Hist. Goth., 41.

$25 \mathrm{~V}$. referencias en M. Risco: $o$. c., pp. 324-328.

26 Asi, por ej., entre los mismos autores transpirenaicos, J.-F. Bladé (o. c., pp. 67-74), el que en no pocos puntos sigue a pies juntillas la línea de argumentación de $\mathrm{M}$. Risco...; v. también M. Rouche (o. c, , p. 60).

27 M. Rouche: Ibid.

${ }^{28}$ El texto del Turonense, que se referencia abajo $\left(n .^{\circ} 29\right)$, dice expresamente que la expedición de Bladastes se dirigió a Vasconia. Ahora bien, según se encargaba de poner de relieve J.-F. Bladé - en la línea de los M. Bouquet, M. Risco, etc.-, «dans le glossaire géographique de Grégoire de Tours, le nom de Vasconia ne s'applique encore que à la Vasconie espagnole. Celui de Novempopulanie continue à designer le territoire de l'ancienne province romaine de Novempopulanie» $(o, c ., \mathrm{p} .6)$. Empero, esta mención de Vasconia en el contexto de la acción punitiva de Bladastes fue interpretada por J. de Jaurgain como la prueba de que para esas fechas los Vascones operaban ya en la Novempopulania (o. $c$., p. 2). En fin, para M. Rouche - quien no deja de subrayar el hecho de tratarse de la primera atestación del término Wasconia en las fuentes del Alto Medio Evo-, el topónimo designaria aqui más precisamente el saltus pirenaico (O. c., p. 504). Pero preguntamos: ¿en su vertiente tarraconense o novempopulana, para traducirlo a términos de la administración romana, o en ambas? Porque Gregorio dice que marchó a Vasconia, y los Vascones - a los que las fuentes clásicas atribuyen, por supuesto, un saltus en el 
tiene que vérselas con el aparato de poder visigodo, sino con los Vascones, quienes por esas fechas empezaban ya, según parece, a ser motivo de preocupación para los merovingios, aunque nada sepamos de actuaciones concretas de aquéllos, que pudieran haber dado razón para ello ${ }^{29}$. De tal expedición - $i \mathrm{y}$ por el hecho quizá de que sólo afectara las relaciones entre Francos y Vascones? - no ha quedado memoria sino en los autores de allende el Pirineo, en Gregorio de Tours ${ }^{30}$, más concretamente. Aun asi, un moderno estudioso francés ha creido plausible hablar al respecto de una maniobra en tenaza. concertada entre el monarca godo y el dux Bladastes. Sólo que éste habría actuado, según se sospecha, siguiendo designios de medro personal - muy en consonancia, en cualquier caso, con la línea de actuación de ciertas grandes familias locales o importadas del área aquitano-novempopulana por esos años, en que, a falta de arrestos para empeños de más envergadura, tienden cuando menos a jugar un papel personal en el área y a marcar las diferencias frente a los amos del Norte- L Lo que sea de esto, en apoyo de la tesis de la concertación entre Leovigildo y Bladastes, a la par que la coincidencia temporal de las acciones respectivas, argüiria el hecho - atestiguado por Gregorio de Tours para un tiempo algo posterior- de las connivencias existentes entre Leovigildo y esa nobleza del área novempopulana, entre la que se cuenta el obispo Amelius de Tarbes y la misma suegra de Bladastes, Leuba ${ }^{31}$. M. Rouche señala sobre eso el carácter gótico del nombre de Leuba ${ }^{32}$, lo que daría pie a pensar - y sería un indicio más - que el dux Bladastes pudiera estar casado con una aristócrata de origen godo. En cualquier caso, y aun admitido el que en las acciones coincidentes de Leovigildo y Bladastes haya que ver el reflejo de una maniobra en tenaza conscientemente preparada, lo que el mismo Turonense refiere del fracaso estrepitoso de la expedición del $d u x$ franco resultaría motivo suficiente ya de por si para que no cupiera insistir en ella como hipotético punto de partida para episodios de dominación franca duradera a este lado de la cadena. A no ser — claro está - que hubiera razones para interpretar la información del Turonense como inficionada por una secreta intención de desquite o como expresión velada de un juicio reprobatorio contra quien, por propia iniciativa y a espaldas de sus jefes, se habria avenido a concertar acciones de ese tipo con los tradicionales enemigos de los Francos, y que en lo sucesivo tampoco se señalaría como un dechado de fidelidad respecto de sus señores naturales ${ }^{33}$.

entorno pireanaico - eran adscritos por las mismas y sin género de dudas a la provincia Tarraconense. $\mathrm{O}$ ¿es que había ya Vascones al otro lado por ese tiempo, antes de que las fuentes empiecen a hablar inequivocamente de sus irrupciones en la Novempopulania? ¿Vascones sensu stricto - el de los autores clásicos-o sensu latiori? Y, si había de los primeros, ¿desde cuándo? Cuestiones - éstas - cuyo análisis detenido nos llevaría mucho más espacio del que aquí disponemos.

${ }^{29}$ Resultan grandemente sintomáticas al respecto las referencias de Ven. Fortunato a los Vascones, de que trataremos luego.

${ }^{30}$ Hist., VI, 12 (ed. de B. Krusch, p. 283).

${ }^{31}$ Hist., VIII, 28. - Sobre el sentido de la aventura politica del obispo Amelius - a inscribir, según el autor, en el horizonte de una Aquitania de relaciones bastante fluidas con la vertiente Sur de la cadena pirenaica, por un lado; cansada de guerras entre los descendientes de Clovis, y dispuesta a jugar sus bazas para asegurarse su margen de independencia frente a los amos del Norte, por otro-, trata de É. Delaruelle: Le diocèse de Bigorre dans l'espace franc de 506 à 587, en Gens et choses de Bigorre [Saverdum] 1967, pp. 20-28.

${ }^{32}$ L'Aquitaine..., pp. 88 y 504 (notas $11-13$ ).

${ }^{33}$ Bladastes, franco de raza él, puede ser visto como un claro exponente de las tensiones centrífugas que aquejaban en las décadas finales del siglo vı al reino franco de Gontrán. Aun haciendo caso omiso de este supuesto acto de deslealtad - para llamarlo de algún modo - del alto funcionario neus- 


\section{LA ENVOLTURA LEGENDARIA Y EL NÚCLEO HISTÓRICO SUBSISTENTE}

\section{Y vuelve de nuevo la pregunta: ¿cabe retener algo del relato del PF sobre el dux Francio de Cantabria?}

Ha solido ser un lugar bastante común entre eruditos e historiadores, cuando la piqueta de la critica histórico-literaria ponía en entredicho la autenticidad de algún documento, o evidenciaba la esencial naturaleza legendaria de ciertos relatos ( $y$, sobre todo, cuanto en tales textos y/o relatos se hallaba vitalmente comprometida la defensa de importantes intereses partidistas, o la de dogmas históricos consagrados por una larga tradición...), el recurrir a la distinción entre la forma y el fondo - entre la envoltura más o menos adecuada de que por necesidad ha de echar mano un mensaje, y el mensaje mismo en su expresión más pura y simple-. Según esto, no es raro el que los historiadores, aun reconociendo las esenciales limitaciones de un texto en lo que respecta a ser expresión fidedigna de los hechos sobre los que informa, se pregunten a veces sobre el núcleo histórico subyacente al mismo. Y algo de eso pasa en nuestro caso. No han faltado, en efecto, estudiosos que, no obstante reconocer las dificultades que presenta el pasaje del PF para ser aceptado a pies juntillas en sus contenidos informativos, se han sentido obligados a preguntarse sobre el fondo histórico que pueda subyacer al mismo ${ }^{34}$.

Ahora bien, puestos a discernir y a aquilatar ese supuesto fondo histórico, una primera gran dificultad reside para estos autores en el hecho de que el PF asocie justamente al nombre de Cantabria ese cuestionado ámbito de dominación franca al sur de la cadena. Y es que ¿de qué Cantabria se trata? ¿De la Cantabria clásica, tal cual venía definida en las fuentes del período romano, y que se extendía desde las fuentes del Ebro hasta la costa de la mar ${ }^{35}$ ? ¿De esa otra Cantabria tardo-antigua, de que hablan algunos ${ }^{36}$, escorada al Sudeste del primitivo emplazamiento cántabro - más precisamente, sobre los primitivos solares de Berones y Autrigones-, y de cuya realidad vendría a ser indicio la persistencia del nombre Cantabria, asociado tanto a la ciudadela sita junto al Ebro, encima de Logroño, como a la vecina sierra homónima? O, en fin, ¿de una Cantabria recrecida que englobaría tanto la clásica como la riojana? $\mathrm{Y}$ es que

trio hacia sus superiores jerárquicos, está ampliamente atestiguada la participación del duque en la fracasada aventura secesionista de Gondovald (582/585), en la que, por supuesto, jugará un papel no poco importante y lo acompañarán algunos jerarcas del área novempopulana que le estaba encomendada. V. al caso el relato de M. Rouche: $o$. c., pp. 66-83, en que se hallarán las referencias pertinentes sobre Bladastes.

${ }^{34} \mathrm{~V}$. algunas referencias en la nota 5.

${ }^{35}$ En punto a los limites de la Cantabria clásica, además de la obra célebre del padre E. Flórez ( $L a$ Cantabria..., Madrid 1768 [=ES, t. 24]), puede verse J. González Echegaray: Los Cántabros, Madrid 1966, más precisamente pp. 20-23.

${ }^{36}$ Desde los dias del padre E. Flórez (o. $c .$, p. 162) no han sido pocos los que han aceptado de una $\mathrm{u}$ otra forma y con mayores o menores matices la idea de un corrimiento del nombre de Cantabria hacia el Sudeste, sobre los primitivos lugares de asentamiento de Berones y Autrigones. En su exposición Flórez habla de la conquista por Leovigildo tanto de la Cantabria clásica - hecho que quedaría fuera de dudas por la referencia expresa del Biclarense (ad a. 574?) a la toma de la ciudad de Amaya en la frontera meridional de su territorio--, como de la Cantabria ciudad riojana - a que se aplicaria mejor el famoso texto de la Vita S. Emiliani (33 [26]), que empuja a pensar en una Cantabria toda próxima al lugar de habitación del anciano cenobita-. V., en todo caso, algunas referencias y precisiones en J. González Echegaray: La «nota».... pp. 71 y ss, y A. Besga: $o$. c., pp. 84-88. 
tampoco faltan modernos historiadores ${ }^{37}$ que, con mayor o menor base de razón, estiman debe entenderse asi la Cantabria de que se habla en ciertos textos tardoantiguos.

Porque, tratándose de la primera Cantabria, la verdad es que se hace dificil imaginar en ella en los dias de Siscbuto un ducado sometido al poder merovingio: por un lado, por la sencilla razón de que en el año 574 Leovigildo anexionó a su reino dicha Cantabria, que tenía una de sus plazas fuertes en Amaya ${ }^{3 \mathrm{x}}$ - sin que con posterioridad se oiga para nada hablar de acciones armadas de los Francos por esa parte ${ }^{39}$-; y, de otro, porque un ámbito de dominio franco tan escorado hacia el Oeste habria derivado en una situación auténticamente insular y del todo excéntrica respecto del mundo de influencias merovingio, del que aquél se veria cortado por el compacto cerco que formaban en derredor las tierras dependientes del reino de Toledo por el Sur, y un extenso no man's land (?), sometido a la influencia de los Vascones o expuesto cuando menos a sus correrías, por el Este y Sudeste. Cabria, en todo caso, la posibilidad de que esa situación de insularidad pudiera a la sazón haberse visto corregida —o aliviada cuando menos - por un cierto tráfico marítimo que, a partir de Burdeos, enlazaba al mundo merovingio con el litoral peninsular, tráfico maritimo del que testimoniarian a su modo ciertos textos cronisticos $^{416} \mathrm{y}$ otros hagiográficos de más dificil tratamiento histórico-crítico ${ }^{41}$, pero que, en cualquier caso, parece estar mejor documentado en el caso de la Galicia sueva ${ }^{42}$ que en el de esta fantasmal Cantabria merovingia de la que hace nos ocupemos el texto del PF.

${ }^{37}$ V., por eje., R. Menéndez Pidal: Origenes del español. Estado lingüistico de la Peninsula Ibérica hasta el siglo XI, Madrid 5.", 1964, p. 469; A. Barbero-M. Vigil: $o$. c., p. 88; L. A. Garcia Moreno: Estudios sobre la administración del reino visigodo de Toledo, en «Anuario de Historia del Derecho Español» 44, 1974, 5-155, aqui concretamente, pp. 139s.

${ }^{3 *}$ Sobre el hecho contamos con tres testimonios principales: uno, del Biclarense (Chron. [ad ann. 574?]); otro, de Isidoro (Hist. Goth., 49); otro, en fin, de Braulio en la Vita S. Emiliani (33 [XXVI]).

${ }^{34}$ Es cierto que algunos han visto en unos versos de Ven. Fortunato, posteriores en todo caso a la conquista de Cantabria por Leovigildo en el 574, el indicio de enfrentamientos posteriores entre los Francos, por un lado, y Cántabros y Vascones, por otro (asi, J. González Echegaray: o. c., p. 76). Sólo que los versos de referencia (Carm., X, 19, vv. 112s), tomados del poema $\mathrm{Ad}$ Galactorium comitem, no le parecen a uno tan claros o definitivos, salvo quizá en lo que suponen - sobre todo, en boca de un personaje tan próximo a las instancias de poder merovingias como Fortunato - de reconocimiento de la personalidad indiscutible de ambos pueblos. Puede verse un atinado comentario del poema, en $\mathrm{M}$. Rouche: $o . c .$, p. 89 y núm. 20 (p. 505). - Lo que sea de esto, no hay que olvidar que, para S. Isidoro -y la observación es de A. Besga $\left(O . c_{\text {. }}\right.$, p. 67)--, Recaredo "acertó a mantener en paz, ordenar equitativamente y gobernar con moderación las provincias que su padre se habia anexionado mediante la fuerza" (Hist. Goth., 54), y que tampoco lo que sabemos de la relación de fuerzas entre Godos y Francos en los años inmediatos parece propiciar la hipótesis de una reconquista de Cantabria por éstos antes del reinado de Sisebuto.

${ }^{40}$ Cfr. Gregorio de Tours: Hist. Franc., V, 41 y VIII, 35.

${ }^{4}$ Cfr. Gregorio de Tours: De miraculis Sancti Martini, IV, 40 (el caso del Mauranus cántabro). -Otros textos hagiográficos, referidos éstos al país de los suevos, Ibid., I, 9 y 11; III, 8; IV, 7 -. V., sobre todo esto, A. R. Lewis: Le commerce et la navigation sur les cótes atlantiques de la Gaule du V* au VIII siècle, en "Le Moyen Age. Revue d'Histoire et de Philologie» 59, 1953, 249-99 y más concret. 269 ss (habla del comienzo de una nueva era en el régimen de intercambios de toda la fachada atlántica, que afecta también en mayor o menor media al Cantábrico).

${ }_{42}$ V. al caso J. Orlandis: Communications et échanges entre l'Espagne wisigothique et la France mérovingienne, en "Annales de la Faculté de Droit de Toulouse» 18, 1970, 253-262, part. pp. 258-261; Id.: Historia del reino visigodo..., pp. 275-277; A. Prieto Prieto: El marco politico-religioso de 
Mas tampoco resulta fácil imaginar un ducado sometido al dominio merovingio en el entorno de una Cantabria estrictamente riojana. Digamos, ante todo, que para ciertos autores ${ }^{43}$ distaria mucho de que pudiera decirse probada la especie que habla de corrimiento del topónimo Cantabria hacia la Rioja en los tiempos tardo-antiguos, "por lo menos hasta mediados del siglo VII" "4. Pero, aun dándola por probada y admitido también por descontado que un dominio constituido sobre los solares primitivos de Berones y Autrigones estaría realmente más cerca de los Pirineos y de otros ámbitos de obediencia franca, no por eso dejaría de hallarse - como la Cantabria de la otra hipótesis - cercado por todas partes de tierras hostiles - bajo dominación goda, por el Noroeste y Sur; formando parte de ese no man's land en que campan por sus fueros los Vascones, por el Norte o Nordeste-; con la particularidad de que la situación excéntrica o de insularidad, de que hablábamos arriba, se habría visto agravada en el caso de un ducado franco riojano por el hecho mismo de hallarse privado de salidas a la mar (a no ser, claro está, que se quiera verlo prolongándose hacia el lado de la costa que perteneció otrora a los Autrigones).

Queda aún la posibilidad de la tercera Cantabria - la que sin dejar de englobar a la clásica se extendería hacia el Sudeste por tierras de Autrigones y Berones hasta más abajo de Logroño en la línea del Ebro-. Pero nos tememos que ni planteada así se libra de sustanciales objeciones la especie que habla de un ducado de Cantabria bajo dominio franco a la altura del reinado de Sisebuto; de hecho y por lo pronto, quedarían en pie en lo esencial, referidas a ésta, las reservas formuladas para las dos hipótesis anteriores.

Pero no vamos a insistir más en este punto de la localización precisa de la Cantabria de que habla el célebre pasaje del PF. Y es que lo que al cabo interesa en el mismo a nuestro objeto no es tanto la verosimilitud de la especie que sitúa precisamente en Cantabria un ducado sometido al dominio franco, cuanto la existencia misma de un ducado franco al Sur de la cadena.

Ahora bien, reconducido el debate a este punto y volviendo a enlazar con la pregunta con que abríamos este epígrafe, interesa recordar aquí que se cifraban en dos principales las reservas de los que se oponían a la especie de un ducado cispirenaico bajo dominio franco: a) se insistía, ante todo, en el hecho de que en los textos tardoantiguos no se registrara una sola referencia - a excepción del comentado del cronista borgoñon- que explícita o implícitamente aludiera a hechos de dominación o asentamiento franco al Sur de los Pirineos; b) se venía a decir luego que, en las escasísimas ocasiones en que las fuentes de la época hablaban de acciones francas episódicas al Sur de la cadena, se ofrecían éstas de naturaleza tal, que resultaba impropio al caso estimar el que de ellas hubieran podido seguirse hechos más o menos importantes y duraderos de dominación.

Se trata, sin duda, de objeciones importantes - lo que explica en buena medida las resistencias que la especie pseudo-fredegariana del ducado franco cispirenaico ha encontrado en la generalidad de los estudiosos modernos mejor informados-; pero que no son decisivas, y pueden incluso ser neutralizadas con relativa facilidad, cuando, como en nuestro caso, vienen a terciar en el estado de la cuestión nuevos e importantes elementos de juicio.

En cuanto a la primera objeción, cabría, en efecto, argumentar que se trata de una época en que la documentación coetánea referida al área septentrional de la Península es, por lo demás,

los concilios bracarenses I y II, en El Concilio de Braga y la fundación de la legislación particular en la lglesia, Salamanca 1975, pp. 67-89.

${ }^{43}$ V., por ej., J. González Echegaray: o. c., A. Besga: o. c., pp. 81-93.

${ }^{44}$ Cfr. J. González Echegaray: o. c., p. 94. V. también A. Besga: o. c., p. 92. 
tan escandalosamente escasa, que el argumento ex silentio no parece deba considerarse decisivo para restar veracidad a informaciones que, como la referida al dux Francio de Cantabria, se recogen una sola vez en la documentación coetánea. De hecho, no resulta difícil espigar en las crónicas del tiempo atestaciones de hechos que se dirian hapax legómena en el sentido estricto de la palabra, pero que no por eso dejan de ser tenidas en cuenta en la práctica historiográfica, y explotadas en mayor o menor medida por ella. Sin ir más lejos, puede uno traer a colación los escuetos pasajes en que Hidacio consigna los episodios relativos a la insurrección bagaude de la provincia Tarraconense ${ }^{45}$, episodios que, como es bien sabido, no cuentan con otro refrendo documental que el del Chronicon del obispo de Chaves, y que, sin embargo, son aprovechados sin complejos en la práctica historiográfica. Etc., etc. Así, pues, si aqui un hapax legómenon recibe un trato distinto, no parece que ello se deba sin más al hecho de que se trate de un hapax. sino al de que la información que vehicula resulta chocante por otros motivos. Entre éstos puede sin duda pesar el de que la impresión resultante del haz de testimonios coetáneos, de que por lo demás disponemos en punto a las relaciones de vecindad entre Godos y Francos por entonces, parece no encajar - o excluir incluso - situaciones como las de un dux de Cantabria pagando tributos por largos años a los reyes merovingios. Pero se trataría, en todo caso, de impresiones resultantes de nuestras propias lecturas o interpretaciones de un haz de testimonios documentales, los que, por otro lado - todo hay que decirlo-, son más bien contados, y se producen a cuentagotas en una sucesión temporal de no pocas décadas, en que las situaciones de indefinición de fronteras entre diferentes ámbitos o esferas de poder no han debido de ser tan raras, sobre todo en áreas marginales.

En cuanto a la segunda objeción, nada tenemos que decir ya, una vez sentado lo anterior. Y es que ese punto b) sólo puede tener sentido o relevancia probativa al caso en el supuesto - excesivo a todas luces, según nuestra manera de ver-de que las referencias documentales existentes agoten en cierto modo el tema de las relaciones de vecindad entre Godos y Francos. $\mathrm{Y}$ ése no sería el caso, según lo expuesto en el apartado anterior, o, cuando menos, no estaría suficientemente probado que lo fuese.

Así las cosas, no parece que en principio pueda negarse algún viso de probabilidad a la especie recogida por el PF, de un supuesto enclave cispirenaico sometido al poder franco.

\section{INDICIOS TEXTUALES QUE ABONARÍAN EL SUPUESTO PSEUDO-FREDEGARIANO}

Aclaremos, antes de pasar adelante, lo que aqui entendemos por indicios en favor de la plausibilidad de la información del PF. No se trata, por supuesto, de indicios positivos univocos - es decir, de referencias textuales que sólo tendrian explicación en el contexto de la noticia pseudo-fredegariana sobre un ducado cispirenaico bajo dominación merovingia-. Se trata a veces de elementos indiciales que en las hipótesis explicativas formuladas hasta el momento no han hallado - que sepamos - una explicación del todo satisfactoria, los que, en cambio, cobrarían una plausible, caso de aceptarse el núcleo del relato fredegariano. Otras, en cambio, se trata de referencias que pueden hallar encaje tanto en éste como en otros contextos hermenéuticos manejados.

En nuestra exposición trataremos de ceñirnos en lo posible a un cierto orden cronológico,

${ }^{45}$ Chron. 125, 128, 140-142, 158. 
que vendrá determinado por la sucesión misma de los hechos a que hacen referencia los indicios allegados.

- En las referencias textuales de que disponemos sobre la toma de Cantabria por Leovigildo, hay dos detalles que de tiempo atrás han venido llamando la atención de los estudiosos, y que, a nuestro entender $-y$ vistas las contradictorias interpretaciones a que se han prestado- no han sido nunca explicados de forma del todo satisfactoria. Uno es que en el texto del Biclarense ${ }^{46}$ se califica como invasores - pervasores - a los que detentaban el poder en la provincia, cuando ésta es atacada por el monarca godo. Y cabe preguntarse: ¿de qué invasores de la provincia se trataba? ¿De Cántabros que incursionaban en territorio godo, como sugiere A. Schulten ${ }^{47}$ ? ¿De Suevos, según ven otros ${ }^{48}$ ? ¿De Vascones quizá, como se le ocurre pensar a M. Rouche ${ }^{44}$ ?

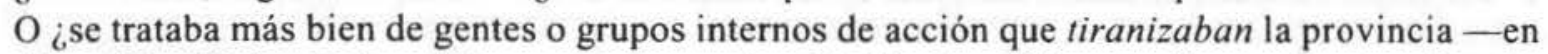
el sentido clásico de la palabra-, como sugiere C. Sánchez Albornoz ${ }^{50}$, seguido por algunos otros $^{51}$ ? Y me pregunto: ¿qué razones hay para que no quepa pensar igualmente en los supuestos súbditos francos de la Cantabria del PF? ¿La de que esos pervasores provinciae se dirian ya derrotados (¿y sojuzgados?) desde los días de Leovigildo según el relato del Biclarense, siendo así que los supuestos súbditos francos cispirenaicos del relato pseudo-fredegariano to habrian sido en los días del rey Sisebuto? A la verdad, de absolutizar el valor de esta objeción, habría que renunciar por igual tanto a la hipótesis que acabamos de formular - a título puramente conjetural, por supuesto-, como, por la misma razón, al pasaje del PF en que se habla de un ducado de Cantabria que se somete a Sisebuto ya entrado el siglo vil; y es que, para el Biclarense, la Cantabria habria sido ya conquistada por Leovigildo varios lustros antes. Pero el hecho es que no son pocos los autores que se tientan la ropa, antes de despachar de forma tan expeditiva la noticia del cronista borgoñón.

- Hay otro detalle - en el conjunto de informaciones referidas a las acciones ${ }^{52}$ de Leovigildo contra Cantabria - que no deja de resultar chocante para los estudiosos. Y es el de que un personaje de excepción, como Braulio, tache de artero y perjuro al rey godo que protagonizó tales acciones. Ahora bien, nos preguntamos: ¿qué significa el que un obispo de la Iglesia hispana, plenamente identificado - por lo que parece ${ }^{53}$ - con la suerte de la patria visigótica, no tuviera empacho en calificar asi a un Leovigildo, al que, a despecho de su fe arriana, no dejaba de considerársele como uno de los máximos fundadores de dicha patria? ¿Es que lo que atacó Leovigildo era algo asi como un Estado de derecho — un dominio de otro príncipe, valga por caso, reconocido como tal en virtud de tratados internacionales o de situaciones de hecho

$46 \mathrm{~V}$. referencia en la nota 38 .

${ }^{47}$ Los cántabros y los astures y su guerra con Roma, Madrid 1962, p. 35.

${ }^{48}$ V., por ej., M. Torres López: Las invasiones y los reinos germánicos de España, en R. Menéndez Pidal (dir.): Historia de España, t. III: España visigoda (414-711 de J. C.), Madrid 4." 1980, aquí concretamente, p. 101; C. Torres Rodriguez: Galicia sueva, La Coruña 1977, p. 246; A. Besga Marroquin: o. c., p. 23, nota 59 .

49 O. c., p. 88.

so Origenes de la nación española. Estudios criticos sobre la historia del reino de Asturias, 3 tt., Oviedo 1972-1975, aqui concretamente, t. I, p. 42.

${ }_{51}$ V., por ej., J. Orlandis: Historia de España. Época visigoda..., p. 94, quien se inclina por ver en tales pervasores a «los dirigentes indígenas cántabros».

52 V. referencia en la nota 38.

s3 V., por ej., su Epist. 37. 
consolidadas por una más o menos larga y pacifica posesión-, el que, por lo mismo, no era permitido atacar, sin contravenir a las normas del derecho o a la palabra jurada? Queden ahi, sin más, esos interrogantes, a partir de los cuales cabría, por supuesto, desarrollar múltiples teorias de indole conjetural.

- Referido a ese mismo año 574, hay un pasaje del Cronicón de Marius d'Avenches, que no ha dejado de suscitar alguna perplejidad. Habla en él de los Langohardi que protagonizaron una incursión en el Vaucluse (Provenza), y llegaron hasta el monasterio de Caunas, donde se aposentaron por muchos dias. "Y luego - prosigue - entablaron batalla contra el ejército de los Francos in Baccis [sic], en donde fueron casi del todo exterminados, a excepción de unos pocos que se libraron mediante la fuga. Pero también los Mauri y otras gentes que tuvieron la osadía de invadir la Provincia de aquéllos fueron derrotados por los mismos Francos» ${ }^{54}$. Reconocemos que las palabras del cronista - tan centradas como parecen por el resto, en su literalidad, en hechos que tienen que ver con el actual Midi francés - dejan muy pocos resquicios para su plausible contextualización en un entorno más próximo al de la Cantabria del PF. Mas ahí está ese locativo in Baccis, que, a falta - muy presumiblemente- de referentes onomásticos más próximos en la historia tardoantigua del área en cuestión, ha movido a un profundo conocedor de la misma ${ }^{55}$ a adscribir esa parte del pasaje - siquiera, a título puramente conjetural - a los Vaccei de otros textos tardoantiguos ${ }^{56}, \mathrm{y}$, a partir de esa adscripción, a buscar un encuadre a la noticia en el contexto de las luchas de los Vascones con los Francos ${ }^{57}$. Pero, como dicho, no es ni mucho menos seguro que el texto de Marius d'Avenches tenga nada que ver con los Vascones.

- Entre el 574-580 suelen datarse unas escuetas referencias de Ven. Fortunato a Cántabros y Vascones: referencias que, empero, resultan de no escaso interés, por un lado, porque son el sintoma de la creciente importancia que iba cobrándose en los destinos de esta parte de Europa la otrora oscura nación pirenaica, y, por otro - y en esto hace más a nuestro caso-, porque a través de las mismas puede, por lo que parece, rastrearse algo sobre las relaciones de vecindad entre Francos y dichos pueblos del norte peninsular.

La primera, escuetísima, se incluye en un poema que Venancio escribió hacia el 570 en honor del emperador Justino II y de Sofia, y se reduce a sendas menciones del étnico Vasco, en la primera de las cuales hace al Vascón vecino del Cántabro, y en la segunda lo alinea en un mismo plano de igualdad junto a otros pueblos que - como el Germano, el Bátavo, el Britano, tachados de bárbaros - eran a todas luces independientes y pesaban lo suficiente en el panorama político de la época como para que se ocupasen de ellos las cancillerías ${ }^{58}$. Ahora bien, no deja de intrigar a los autores el hecho de que, en un momento en que no hay aún noticias de enfrentamientos entre Francos y Vascones - al menos, del lado de allá de la cadena pirenaica-,

${ }^{54}$ Chronica, ad ann. 575 (ed. de Th. Mommsen en $M G H A A, 11^{2}$, Berlín 1984, p. 239).

55 M. Rouche: $o . c$., p. 504, nota 13.

s6 Cfr. S. Isidoro: Etym., 9, 2, 107s; item J. Vives: Inscripciones cristianas de la España romana y visigoda, Barcelona 2. ${ }^{\text {a }}$ 1969, núm. 287. Empero, no hemos podido documentar, si hacemos abstracción de ésta de Marius d'Avenches - dubitativamente y a titulo conjetural avanza M. Rouche-, otras atestaciones de la reducción Vaccei o Baccei $=$ Vascones anteriores al texto isidoriano de las Etimologías.

57 Para M. Rouche, «cette attaque faite en 574 expliquerait en 581 la concertation entre Léovigild et Bladastes et les deux lettres de Fotunat» (Ibid). Lo que no sería, en nuestra modesta opinión, sino montar conjeturas sobre conjeturas, si se tiene en cuenta que todo el entramado hermenéutico descansa sobre la reducción -ipuramente conjetural! - de Baccis = Vacceis $=$ Vascones .

${ }^{58}$ Cfr. Carm., Append. II, 2, vv. 29 s y 83 s. 
un áulico como Fortunato nombrase a éstos en un mismo plano de igualdad junto a otros pueblos que sí constituian de tiempo atrás motivo de preocupación para sus amos. Llama también la atención el hecho de que hiciese vecinos a Cántabros y Vascones, relegando al silencio a los pueblos - Autrigones, Caristios, Várdulos - que en la etapa imperial se intercalaban entre unos y otros. Vascones vecinos de los Cántabros, por un lado; y Vascones, que son puestos en un mismo pie que otros que de antaño inquietaban a los reyes francos... Pero ¿dónde resultaban amenazadores para el poder franco tales Vascones, los que, según ha venido repitiéndose sobre la base de un célebre texto de Gregorio de Tours ${ }^{59}$, no lograron hasta el 587 trasponer los puertos pirenaicos, para lanzarse sobre la plana novempopulana?

En otro poema, dedicado al rey Chilperico en ocasión del sínodo de Berny (año 580), Fortunato muestra a éste sojuzgando junto a su padre a los Vascones ${ }^{60}$. La referencia ha sido a veces interpretada como una alusión a la famosa marcha de los «cinco reyes» sobre Caesaraugusta y la Tarraconense, de que tratamos arriba ${ }^{61}$, marcha en la que el ejército franco pasó por Pampelona, ciudad vascona, según se hace constar expresamente en las fuentes. Pero no existe certeza alguna sobre que tal interpretación sea la ajustada. Habría que decir, por el contrario, que resulta altamente improbable que el poeta pudiera imaginarse a Chilperico tomando parte en esa expedición ${ }^{62}$, siendo así que el futuro rey de Soissons y de Paris no hacía mucho que había dejado los pañales cuando su padre Clotario y Childeberto se abrían paso hacia el Sur a través de los puertos pirenaicos. Habría que hallarle, en consecuencia, un mejor encuadre temporal a esa referencia venanciana a un Chilperico que combate junto a su padre a los Vascones; y ello, por lo que parece deducirse del texto, antes del 561 como terminus ad quem, fecha en que desaparece de la escena Clotario I. Ahora bien, ¿dónde combate Chilperico a los Vascones, si la irrupción de éstos sobre la plana novempopulana se retrasa, según se nos dice sobre la base del conocido texto de Gregorio de Tours, hasta el 587, año más o menos?

- Hay otro pasaje del Biclarense, que, a nuestro entender, merece ser considerado en este contexto, y es el que registra la ocupación de Vasconia por Leovigildo ${ }^{63}$. No vamos a extendernos aquí sobre lo mucho que se ha escrito en punto a las circunstancias que, según algunos ${ }^{64}$, concurrieron en el evento, o sobre el alcance de la acción protagonizada por el monarca

${ }^{54}$ Hist., IX, 7 (ed. de B. Krusch, p. 420).

60) Carm., IX, I, 73-74. Sobre el alcance del testimonio conjunto de V. Fortunato, puede verse, por ej., A. Barbero. M. Vigil: o. c., pp. $51 \mathrm{~s}$ y $55 \mathrm{~s}$; M. Rouche: $o . c$., pp. $88 \mathrm{~s}+$ notas 7 y 20 del capitulo correspondiente (pp. 503 y 505).

$61 \mathrm{~V}$. los textos de referencia en las notas 22-24.

${ }^{62}$ El que sí parece, en cambio, tomó parte en esa expedición fue el Leontius, futuro obispo de Burdigala, al que Fortunato dedica algún que otro poema. En uno de ellos lo muestra «versus ad Hispanas acies cum rege sereno", y añadiendo de esa forma nuevos brillos a los muchos que le correspondian por otros conceptos (Carm., I, XV, vv. 9s).

${ }^{63}$ Chron. [ad ann 581?] (ed. de Th. Mommsen, p. 216).

${ }^{64}$ E. A. Thompson (The Goths..., p. 70) estima que la operación de Leovigildo contra los Vascones pudo estar motivada por un eventual ataque previo de éstos a la ciudad de Roda (¿Rosas?). Le da pie a pensar en ello una leyendo monetal que conmemora la entrada victoriosa del rey godo en la citada localidad, y que, por todas las trazas, habria que datar entre 580 y 584 . Ahora bien, habida cuenta, por un lado, de que por esos años y en relación con el monarca godo las fuentes sólo documentan las luchas que le enfrentaron a su hijo Hermenegildo y a los Vascones, y considerando, por otro, que Roda - identificado con Rosas - se hallaba notablemente lejos del escenario agitado por la sublevación de aquél, apenas habría dudas para el historiador británico sobre que fueron los Vascones los que protagonizaron 
godo ${ }^{65}$. Retendremos tan sólo que, para ciertos autores - y según quedó señalado arriba, al hablar de la acción antivascona del $d u x$ franco Bladastes ${ }^{66}$ - , se habria tratado de una operación en tenaza contra los Vascones de uno y otro lado, operación en la que la representación franca ${ }^{67}$, vinculada por nacimiento o azares de gobierno al ámbito circumpirenaico occidental, se habría supuestamente implicado por oscuros móviles de poder o de medro personal en la zona. Extraña un tanto, sin embargo, que quienes han hablado de concertación de operaciones en tenaza entre Godos y Francos, por una parte, y subrayado, por otra, la voluntad de reunificación de todo el territorio peninsular, que anima al gran caudillo godo, no hayan apurado más el margen de maniobra hermenéutico al que se presta el texto del Biclarense en lo que dice sobre que aquél se anexionó sólo una parte de Vasconia. Y es que cabe justamente preguntarse: ¿Por qué sólo una parte? ¿Por impotencia o incapacidad para hacerse con el resto? No parece muy convincente esta hipótesis para algunos, a la que le faltaria - según se encargan de señalar- el más mínimo apoyo en las fuentes ${ }^{6 x}$. Pero cabe seguir preguntándose: ¿por qué, entonces? ¿Acaso porque en las conversaciones previas a la concertación de esa operación en tenaza los atacantes se habían fijado limites a eventuales acciones de ocupación posteriores? El margen de maniobra conjetural a que se presta la interpretación del pasaje no excluye, como se ve, ni mucho menos la hipótesis de una Vasconia cuyo dominio estuviera repartido entre Godos y Francos, y eso hacia el 581, cuando nada sabemos todavia de que el nombre de Vasconia recubra otros territorios que los de la vieja provincia Tarraconense.

- Vamos a dar fin a nuestro repaso de los indicios de orden textual, que, a nuestro modo de ver, abonarian en cierto modo la especie pseudo-fredegariana de un ámbito de dominación franco al sur de los Pirineos, volviendo al punto mismo de partida, y sometiendo a análisis algunos extremos no tocados del pasaje del cronista borgoñón, que da pie a estas consideraciones.

$\mathrm{Y}$, una vez metidos a ello, interesa destacar, ante todo, el formidable e insólito elogio que tributa aquél a Sisebuto, un monarca godo del que sabe, sin embargo - si es que responde a la verdad lo que él mismo añade a continuación-, que hizo sufrir algún tipo de descalabro o de disminución de poder a sus señores naturales, los reyes francos, ya que un ducado que antes estaba sometido y rendía tributo a éstos, fue anexionado por aquél al reino de los Godos. Y surge una primera pregunta: ¿Cabe suponer en buena lógica que, de no ser ciertos en algún sentido los hechos que relataba, un fiel vasallo de los reyes francos se inventara una especie así, que, en cualquier caso y en su acepción literal, difícilmente podía ser interpretada sino como un desdoro

el ataque referido (a señalar que son varios los que estiman justificada esta conjetura, entre los que el mismo M. Rouche: o. c., p. 504, nota 10).

${ }^{65}$ Cfr. A. Besga: $o$. c., pp. 26-33, en que se hallarán más referencias. Sobre las identificaciones propuestas para el Victoriacum del texto del Biclarense, V. A. Azkárate (Arqueologia cristiana..., páginas 495-497), quien - en contra de los C. Sánchez Albornoz, A. Barbero-M. Vigil, etc.-estima menos fundadas las reducciones que apuntan a la llanada alavesa, y propone su ubicación más al Este, dentro del territorio vascón clásico.

66 V. supra el texto relativo a las nn. 29-33.

${ }^{67}$ Aludimos, claro está, al dux referido y al círculo nobiliario que lo apoyaba, del que formaba parte muy probablemente ese Amelius, obispo de Tarbes, al que nos referiamos más arriba ( $v$, texto relativo a la n. 30) y al que junto con Leuba, la suegra de Bladastes, vemos algún tiempo después metido en oscuros tratos con el rey Leovigildo, a espaldas, por supuesto, de los reyes mevoringios y en contra de los intereses de éstos. V. en la n. citada la referencia al pasaje de Gregorio de Tours, junto con las de los comentarios que el mismo ha suscitado.

${ }^{68}$ V., J. J. Sayas: o. c., p. 394. 
para el nombre de su pueblo? Se sospecha no sin razón que autores de obediencia merovingia pudieran, llegado el caso, estimar un deber cubrir con un discreto velo de silencio ciertos hechos menos favorables al nombre de la patria franca ${ }^{(6)}, o$, cuando menos, tratar de restarles importancia, interpretándolos en función de supuestos de orden moral y teológico, que lavaran en cierto modo o dejaran a salvo el prestigio de la nación y de sus reyes ${ }^{70}$. Lo que extraña más es que, puestos a faltar a la verdad, se inventaran hechos que redundaran en desdoro de su

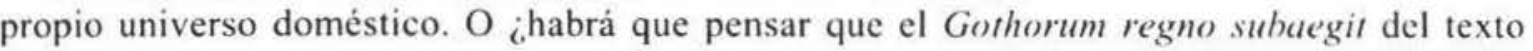
pseudo-fredegariano ha de ser interpretado en un contexto distinto del de una movilización armada? ¿En el de unas negociaciones pacificas, quizás? Sólo que este posible nuevo giro interpretativo nos lleva a preguntarnos sobre las relaciones de vecindad entre Visigodos y Francos en los días de Sisebuto.

Es sabido, en efecto, que el tono de tales relaciones no fue siempre el mismo desde que, en los ya lejanos dias del reino visigodo de Tolosa, empezó éste a sentir sobre sus fronteras la presión amenazante de las hordas francas de Clodoveo, presión que habría determinado en parte -o acentuado, cuando menos- la corriente inmigratoria goda que se produce sobre la Península aun antes de la fecha fatidica del 507 (Vouillé) ${ }^{71}$. Hubo, sin duda, no pocas veces momentos de tensión, que desembocaron en la acción armada. Pero los hubo igualmente presididos por una voluntad de entendimiento y de arreglo pacifico de las desavenencias, que se sellaron a veces por diferentes alianzas matrimoniales. La politica de acercamiento entre Godos y Francos conoció un primer episodio en el enlace de Amalarico con Clotilde, la hija de Clodoveo, enlace que, empero, lejos de servir a la causa de la paz, parece sirvió sólo para enconar aún más las relaciones entre ambos pueblos. Siguieron, en los días de Atanagildo, las uniones de sus hijas Brunekhilda y Gailswintha con los hijos de Clotario, Sigeberto y Chilperico respectivamente, aunque tales uniones en lo desigual de sus vicisitudes y desenlace tampoco supusieron el punto de arranque de la nueva era de paz, que se esperaba. En fin, los enlaces que Leovigildo concertó para sus hijos Hermenegildo y Recaredo - con Ingunda, hija de Sigeberto de Austrasia y de Brunekhilda, en el primer caso; con Rigunthis, hija de Chilperico de Neustria y de Fredegunda, en el segundo-, o el que Witérico concertó años después para su hija Ermenberga con Teodorico II de Borgoña - nieto de la célebre Brunekhilda - supusieron otros tantos pasos más - no todo lo afortunados que fuera de desear - en el intento de consolidar un clima de paz en las relaciones entre Francos y Visigodos.

${ }^{69}$ El mismo Gregorio de Tours - que es, conviene recordarlo, un representante de la aristocracia galo-romana, que sabe muy bien, llegado el caso, marcar distancias frente a los amos del Norte - se creerá, asi y todo, obligado a echar un discreto velo de silencio sobre ciertos descalabros que sufrieron los príncipes merovingios en sus enfrentamientos con los Godos. V. por ej., su relato de la expedición de Clotario I y Childeerto sobre la Tarraconense en el 541 (Hist. Franc., III, 29), en que para nada se oye hablar de los desastres que, según Isidoro (Hist. Goth., 41), les habria infligido el duque godo Theudisclo. Lo cierto es que tampoco la Chron. Caesaraugustana - que es, según se cree, el testimonio más inmediato a los hechos por cercanía espacial y de tiempo- dice nada de acciones de represalia de los Godos contra el ataque desolador de los merovingios (Ad ann. 542).

${ }^{70} \mathrm{~V}$., por ej., los relatos que ofrece el mismo Gregorio sobre las expediciones protagonizadas por Gontran en el 585 y 589 contra la Septimania (Hist. Franc., VIII, 30 y IX, 31), relatos en los que, si no se silencian los descalabros sufridos, se diria atenuarse la significación de los mismos y, en todo caso, descargarse de responsabilidades a los titulares de la realeza, achacando los resultados negativos al comportamiento indigno o inadecuado de los subordinados.

7 Chron. Caesaraug., ad ann. 494 y 497. 
No es que los esfuerzos de paz que se protagonizaron por uno y otro lado se redujeran a esos episodios, que acabaron en bodas de más o menos trágicos destinos y de más o menos infausta memoria "2. Si es que aqui nos hemos fijado particularmente en ellos, es por una circunstancia que por lo general concurria en las negociaciones que llevaban a la concertación de una boda, y era la práctica de la Morgengabe o Morganegiba, a que se refiere en alguna ocasión Gregorio de Tours ${ }^{73}$, práctica usual entre los Germanos y que consistía en un presente que el desposado hacia a la recién casada a la mañana siguiente del día de boda, como reconocimiento y recompensa de la virginidad por ella aportada. Ahora bien, sabemos que tales regalos podian muy bien suponer la concesión del dominio sobre ciudades o territorios más o menos importantes; así, en el caso de Gailswintha -la hija de Amalarico, que casó con Chilperico I-, la Morgengabe que le hizo éste comprendia las civitates de Burdeos, Limoges, Cahors, Béarn y Bigorre, las que, muerta Gaislwintha y a falta de herederos más directos, reivindicaria para si su hermana Brunekhilda ${ }^{74}$. Sabemos también que tal práctica no era privativa de los Francos, documentándose casos de príncipes godos que negociaron sus correspondientes aportaciones al solicitar la mano de las princesas merovingias ${ }^{75}$. Siendo esto asi, ¿se nos permitirá avanzar - a título puramente conjetural, desde luego - la hipótesis de que princesas francas, al igual que Gailswintha, hubieran podido hacerse con la titularidad de dominios más o menos extensos a este lado de la cadena, dominios bajo control godo - más o menos teórico, más o menos efectivo- al principio, pero que, con posterioridad, por mor de los avatares sucesorios, pudieran haber pasado a manos francas? Cabe legitimamente suponer, cuando menos, que Clotilde, la hija de Clodoveo que casó con Amalarico, y asimismo Ingunda, la hija de Sigeberto que lo hizo con Hermenegildo, recibieran de sus cónyuges respectivos la correspondiente dote y Morgengabe, dotes que, al morir sus titulares sin posteridad reconocida a este lado de la cadena pirenaica ${ }^{76}$, pudieron acaso venir a parar a manos de sus parientes transpirenaicos. Como va dicho, avanzamos nuestra hipótesis a título puramente conjetural, pero estimándola, en todo caso, no exenta de ciertos visos de plausibilidad, visto lo que sucedió con la herencia de Gailswintha. Ahora bien, ¿qué es lo que podía suceder, cuando tales dotes o Morgengabe incluían tierras de dominio incierto, es decir, derechos más o menos fundados sobre marcas o civitates a conquistar, como parece fue el caso en más de una transacción entre príncipes germánicos por ese tiempo ${ }^{77}$ ? ¿Deberia extrañarnos tanto el que de tales dotes, constituidas sobre la base de tierras a reganar o de dominios de suerte fluctuante, no hubiese apenas quedado rastro en la documentación?

72 Sobre relaciones entre Godos y Francos en general, v. J. Orlandis: Communications...; justo en las décadas que preceden el reinado de Sisebuto, v. A. Isla Frez: Las relaciones entre el reino visigodo $y$ los reyes merovingios a finales del siglo vi, en «España Medieval» 13, 1990, 11-32.

${ }^{73}$ Hist. Franc., IX, 20.

74 Ibid.

${ }^{75}$ V. por ej., Gregorio de Tours: Hist. Franc., VI, 18

${ }^{76}$ No sabemos que Clotilde dejase posteridad de sus cortas y turbulentas relaciones con Amalarico, ni que el hijo de Ingunda y Hermenegildo, caido junto con su madre en manos de los Bizantinos cuando huían de Leovigildo, pudiese hacer efectivos sus derechos hereditarios al morir sus progenitores. Muerta Ingunda cuando junto con el hijo era conducida a Bizancio por los imperiales, el rastro de éste se pierde en la ciudad imperial, de donde trataron en vano de rescatarlo su abuela Brunekhilda y Childeberto II.

77 No puede uno menos de recordar el caso del célebre reino tolosano de Chariberto II (c. 629/632), reino que, constituido en favor del mismo por Dagoberto I, estaba formado en buena parte por territorios o civitates de dominio incierto y/o a reganar a los Vascones (v. M. Rouche: o. c., pp. 90-92). 
Un dato o indicio: por la correspondencia del conde Búlgar venimos --casualmente y a posterioria enterarnos de un caso de cesión de dominios o plazas fronterizas entre gobernantes godos y francos, del que nada nos habian dicho los cronistas habituales de tales hechos. Por Búlgar sabemos, en efecto, que Recaredo - en momentos de buenas relaciones entre los pueblos respectivos, sin duda - cedió a Brunekhilda las plazas de Juvignac y Corneilhan en la diócesis de Béziers, plazas que años más tarde el lugarteniente del rey Gundemaro en la Septimania se encargó de retomar y poner a buen recaudo como medida de represalia por el trato infligido por Teodorico Il y Brunekhilda a los enviados godos Tatila y Guldrimiro ${ }^{7 x}$, los que, por cierto, habrian sido retenidos por orden de aquéllos en el actual Pays Basque, de ser correcta la reducción del in locum Irupinas del texto por Saint-Pierre-d'Irube, propuesta por M. Rouche ${ }^{79}$.

$\mathrm{Y}$ puesto que estamos hablando de las vicisitudes que las relaciones de vecindad entre Godos y Francos conocieron al paso de los años, no esté tal vez fuera de lugar, volviendo al texto que da pie a estos comentarios, subrayar aqui el hecho de que el cronista atribuya precisamente a Sisebuto la recuperación de ese supuesto ducado franco de Cantabria. Un Sisebuto que, no lo olvidemos, es presentado por el mismo bajo la luz más favorable... Un Sisebuto que, por otro lado, protagonizó un insólito caso de incursión real en los terrenos de la literatura hagiográfica, redactando una Vita Desiderii que ha sido modernamente interpretada como una obra de insoslayable intencionalidad politica: una obra por la que el rey godo, a cambio de hacer una condena sin paliativos de las formas de gobierno de Teodorico de Borgoña y de su abuela la célebre Brunekhilda (¡una princesa visigoda, no conviene olvidarlo!), habria tratado de granjearse las voluntades de aquellos sectores de la población austrasio-borgoñona, que pudieron haberse sentido perjudicados por la política de los citados príncipes, y, sobre todo, de atraerse a Clotario II - el nuevo árbitro de la situación en el mundo franco desde el 613 -, para de esta gisa promover un clima de entendimiento y de buenas relaciones entre Godos y Francos ${ }^{80}$. Ahora bien, tratándose de un monarca godo así, bienquisto de círculos influyentes de la población austrasio-borgoñona $\mathrm{y}$, sobre todo, acreedor a un singular favor del detentador único de la realeza entre los Francos, ¿qué sentido tiene que un clérigo borgoñón le atribuyera éxitos como el que representa la recuperación del ducado de Cantabria, un ducado que se reconoce perteneció otrora a los Francos? ¿Inventaba de punta a punta el PF, o se hacia eco de algo realmente sucedido en el nuevo clima de relaciones que inauguraban los dramáticos sucesos de 613? ¿Algo, por ej., como la devolución al monarca visigodo - en muestra de agradecimiento por el favor recibido con la redacción de la Vita Desiderii- de un dominio franco sito en la vertiente sur de la cadena pirenaica? Como no puede menos de ser, dejaremos la pregunta en suspenso; pero no sin antes volver a insistir en el hecho de que las relaciones de vecindad entre Godos y Francos y la repartición de las respectivas áreas de poder pudieron no ajustarse tan rigidamente a los simplistas esquemas a que nos ha acostumbrado la historiografia posterior, de que puede ser un indice el hecho ya apuntado de enclaves de dominio franco, como los de Corneilhan y Juvignac, sitos en la provincia septimana.

${ }^{7 \times}$ Ed. W. Gundlach en MGH Epist. III: Merowingici et Karolini Aevi I, Berlín 1957, pp. 680s Para J. Fontaine (King Sisebut's Vita Desiderii and the Political Function of Visigothic Hagiography, en Ed. James [ed.]: Visigothic Spain. New Approaches, Oxford 1980, p. 121, n. 2), los lugares citados de Corneilhan y Juvignac, en el actual departamento de Hérault, habrian posiblemente formado parte de aquellos dominios de la dote de Gailswintha que, a la muerte del rey Gontran y según la letra del tratado de Andelot, habrian revertido sobre su hermana Brunekhilda.

${ }^{79}$ L'Aquitaine..., p. 240.

${ }^{80}$ Cfr. J. Fontaine: o. c., pp. 93-129. 
- Como apéndice a este epígrafe sobre los indicios de índole textual que abonarían el supuesto pseudo-fredegariano de ámbitos de dominación franca a este lado de la cadena pirenaica, vamos a dedicar unas pocas palabras al tema de los limites de la Gallia Comata por este lado del Pirineo occidental, tema que para algunos pudiera tener algo que decir en el asunto que nos ocupa.

Como es sabido, la cuestión - resuelta de modo más o menos razonable y satisfactorio para los tiempos clásicos ${ }^{\times 1}$ - se suscita fundamentalmente aqui en razón de unos pocos textos altomedievales de origen peninsular - de unos de Eulogio de Córdoba, sobre todo-que darian pie a pensar que bajo tal denominación geográfica pudieran a partir de cierto tiempo haber sido comprendidos ámbitos territoriales que caen de este lado de la cadena pirenaica. Es decir, que, en el oscuro período que sigue al colapso del orden romano en el área y al abrigo de circunstancias como las que propician la afirmación del expansionismo vascón, el límite clásico entre la Galia e Hispania pudiera haberse difuminado un tanto en la utilización que los eruditos habrian hecho de tales términos, y no ajustarse al eje pirenaico de modo tan estricto como en la Antigüedad clásica o en los tiempos modernos. Y, claro, se haría obligada la pregunta - turbadora pregunta - sobre las razones que habrian determinado tal deslizamiento onomástico...

Ha sido C. Sánchez Albornoz el que entre los modernos estudiosos ha abordado de forma más especifica el tema, analizando, por un lado, los escasos textos que han dado pie al planteamiento del mismo, $y$ haciéndose eco, por otro, de las interpretaciones que han venido formulando al caso los autores ${ }^{{ }_{2}}$. Pero mucho nos tememos que en sus conclusiones, al incluir sin titubeos dentro de la Gallia Comata «la zona alavesa y guipuzcoana» y al dudar, por contra, que en el uso que se hacía de tal término a mediados del siglo ix se incluyese la Vasconia ultrapirenai$\mathrm{ca}^{\mathrm{x}}$, no haya ido más allá de lo que permiten dichos textos, interpretados en su justa luz.

El hecho es que, si excluimos la calendación de un diploma del cartulario de Siresa ${ }^{84}$ - diploma sobre cuya autenticidad, como el mismo S. Albornoz reconoce, se ha suscitado más de una duda-, sólo tendriamos los referidos pasajes de S. Eulogio para tratar de esta cuestión. Ahora bien, entre éstos hay dos que de forma indubitable, a nuestro modo de ver, sitúan los límites de la Gallia Comata en el eje pirenaico. Ambos derivan de la célebre epístola del cordobés al obispo Wiliesindo de Pamplona. En el primero habla de las razones que lo detuvieron más de la cuenta en los cenobios pirenaicos durante su viaje en busca de unos hermanos ausentes, y que se cifraban en el clima de revuelta imperante a la sazón en el reino franco, que hizo que no sólo la Gothia, sino que «la misma Gallia Comata que limita con Pamplona y los Sebúricos» se alzase en contra del rey Carlos ${ }^{85}$. El otro viene líneas abajo en la misma epístola, y habla de la ida del cordobés al monasterio de San Zacarias, asentado - precisa - «al pie de los Pirineos, en los puertos de la susodicha Galia, donde tiene sus fuentes el río Aragus, que recorre Seburi y Pamplona y se arroja en el río Cántabro [Ebro]» ${ }^{86}$.

${ }^{2}$ V. s. v. Comata Gallia en A. Pauly-G. Wissowa: RE, IV' [VII], Stuttgart 1900, cc. 604s.

${ }^{82}$ Sobre la posible localización de la Gallia Comata, en ID. Vascos y navarros..., pp. 333-337.

83 Ibid., p. 336.

${ }^{84}$ Ed. de A. Ubieto Arteta, Valencia 1960, p. 20.

${ }^{85}$ Espitula tertia ad Wiliesindum, ed. J. Gil en Corpus Scriptorum Muzarabicorum, Madrid 1973 , t. II, pp. 497-503, aqui concr. p. 497 s.

${ }_{86}$ Suena asi el pasaje en su tenor original: Et maxime libuit adire beati Zachariae ascysterium, quod situm ad radices montium Pyrenaeorum in praefatae Galliae portariis, quibus Aragus flumen oriens rapido cursu Seburim et Pampilonam irrigans amni Cantabro infunditur, quod famosissimis in exercitatione regularis disciplinae studiis decoratum toto refulgebat occiduo. (O. c., cap. 2, ed, cit. de J. Gil, p. 498). 
Ahora bien, estos pasajes no parecen sino reafirmar la teoria que sitúa en el eje pirenaico el limite entre Gallia Comata e Hispania. Induce a pensar asi la afirmación expresa de Eulogio sobre que la referida Gallia limita con Pamplona y los Sebúricos. Bien es verdad que estos términos han podido ser a veces interpretados como referidos a simples núcleos de población - los de Pamplona y Zubiri, concretamente-, y que, en base a ello, se ha podido desplazar en mayor o menor grado hacia el Sur o el Sudoeste el límite entre la Gallia Comata e Hispania, haciendo entrar en la primera determinadas porciones de la vertiente cispirenaica, aledañas de las citadas localidades. Pero, según observaba ya G. Balparda ${ }^{\times 7}$ en contra de las elucubraciones de J. de Jaurgain ${ }^{\mathrm{x}} \mathrm{y}$ de otros, tal interpretación ni es la única posible, ni es la que mejor se adecúa al sentido general de los textos del autor cordobés. Dejando aquí ahora de lado la cuestión de si había a la sazón en el enclave del actual Zubiri un núcleo importante de población que, como el de Pamplona, pudiera servir a Eulogio como punto inteligible de referencia, observaremos que en el uso común del tiempo términos como el de Pamplona servian a menudo para designar señorios, colectividades o áreas territoriales. Pero hay más, y es que tal interpretación viene avalada por lo que luego refiere el mismo Eulogio sobre el monasterio de S. Zacarías, ubicado - dice - «al pie de los Pirineos, en los puertos de la susodicha Galia, donde tiene sus fuentes el río Aragus, que recorre Seburi y Pamplona y se arroja en el rio Cántabro». Ahora bien, apenas existen dudas de que ese monasterio de $\mathrm{S}$. Zacarias, que celebra tan calurosamente el cordobés, viene a ser el mismo que el célebre de Siresa en el valle de Hecho ${ }^{x y}$. En efecto, sabemos, por un lado, por Eulogio mismo que el abad de ese monasterio de S. Zacarias se llamaba Odoario ${ }^{*}$, al igual que «el abad del monasterio serasiense», al que Wiliesindo deberá encargarse de saludar en su nombre ${ }^{\text {\%. }}$. Pero está, luego, que cuadran perfectamente con el monasterio serasiense todos los datos explicitados por Eulogio sobre la situación del de S. Zacarias, y ello sin necesidad de inventarse - como lo han hecho algunos, entre los que el mismo G. Balparda ${ }^{92}$ - supuestos errores de apreciación en el cordobés. Admitida, en efecto, la identidad del monasterio de S. Zacarías y del de Siresa, se entiende por qué Eulogio hable de un río Aragus que riega Pamplona y Seburi, para arrojarse en el Ebro. La dificultad que se inventan algunos para aceptar la traducción de Aragus por Aragón viene condicionada de hecho por una previa cuanto gratuita identificación de Seburi con Zubiri, identificación sin otra base que la de una cierta similitud fonética, y que hoy puede ser descartada del todo, al documentarse justamente en un diploma del cartulario serasiense el topónimo

*7 Historia critica..., pp. 176-178.

${ }^{88}$ La Vasconie..., t. I, pp. 128-130. No vemos, de todos modos, por qué critica Balparda a Jaurgain en ese punto concreto de la interpretación de Pampilonem y Seburicos como simples núcleos de población, ya que, si lo hemos leido bien, Jaurgain ve a sla Gaule chevelue, voisine du royaume de Pampelume et des terres de Zubiri» (o. c., p. 129).

*9 Un historiador tan concienzudo como J. M. Lacarra pudo vacilar en algún momento al respecto (v. Id.: Las más antiguas fundaciones monásticas en el paso de Roncesvalles, en Homenaje a D. Julio de Urquijo, t. I, San Sebastián 1949, pp. 91-108, concret, pp. 94s.); pero más tarde no parece albergar la minima duda sobre tal identificación (asi, en la Historia politica del Reino de Navarra desde sus origenes hasta su incorporación a Castilla, 3 tt., Pamplona 1972-1973, concret. t. 1, pp. 96s). Ya antes abogaba por esta interpretación E. Lambert: Le voyage de Saint Euloge dans les Pyrénées en 848, en Estudios dedicados a Menéndez Pidal, IV, Madrid 1953, pp. 557-567.

${ }^{90}$ Epist. ad Wiliesindum, cap.2.

9I Ibid., cap. 13.

${ }^{92}$ O. c., p. 177. 
Schori ${ }^{\text {yz }}$, referido a una tierra sita en el alto Aragón, a orillas del rio homónimo, según todas las $\operatorname{trazas}^{94}$.

El tema podria decirse definitivamente zanjado tras lo expuesto, si no se dieran en el mismo Eulogio los elementos que han venido a complicarlo de manera inextricable. El pasaje decisivo en ese sentido es uno que viene en su Memorialis Sanctorum, y habla de un Sanctius, originario ex Alahensi oppido Galliae Comatae. que, reducido a cautividad en su adolescencia $\mathrm{y}$ adscripto después inter militares regis pueros, fue al cabo martirizado ${ }^{45}$. Ha sido este texto, en efecto, el que, a partir de la reducción del citado oppidum Alahense con la mansio Alha del Itinerarium Antonini" - mansio de la vía Asturica-Burdigala, localizada comúnmente en torno de la actual Salvatierra en Álava--, ha hecho que autores como J. M. Lacarra ${ }^{47}$ o C. Sánchez Albornoz" hayan venido a hablar, aunque con matices diferenciadores, de una Gallia Comata que se habria extendido por tierras de Guipúzcoa y Álava. Y hay que reconocer que se avienen bien con tal identificación algunos extremos que cabe inferir de la noticia eulogiana: asi, el de que el santo - capturado en temprana edad - hubiera nacido - o vivido al menos - en tierras abiertas a las azeifas musulmanas, o el de que se hubiese llamado Sanctius, nombre que no disuena sino todo lo contrario en ese umbral del mundo vascón, en el que los Sanchos se documentan con profusión por entonces. Pero no convendria exagerar la fuerza probativa de tales coincidencias — por llamarlas de algún modo-. De hecho, las razzias musulmanas también llegaron a la sazón a afectar, aunque mucho más raramente, a la vertiente transpirenaica ${ }^{9 \%} \mathrm{o}$ a

"Cartulario de Siresa, ed. de A. Ubieto Arteta, Valencia 1960, pp. 35-38.

${ }^{4}$ V. en este punto J. Canal Sảnchez-Pagin: Los rucones un pueblo vasco-navarro, en [I] Congreso General de Historia de Navarra, Pamplona 22-27 de septiembre de 1986. 2. Comunicaciones: Archivistica, Prehistoria. Edad Antigua [= «PV» 48, Anejo 7, 1987], pp. 349-362, part. pp. 357-359.

" De Sanctio martyre. Sanctus vero Sanctius auditor noster, laicus adolescens, ex Albensi oppido Galliae Comatae, olim captivatus, nunc autem inter militares regis pueros liber praescriptus, et regalibus annonis nutritus, in aedem urge regia eadem professione, nonas junias, aera qua supra [scil., octingentesima octuagesima nona $=851$ ] feria sexta, postratus est, et afixus (II, II, ed. Migne en PL 115, 771). No esté quizá de sobra anotar aquí que A. Morales leyó Alahensi en el manuscrito, y que pasó a cambiarlo por Albensi basándose en los textos de Plinio (Nat. hist., 3, 26) y Ptolomeo (Geogr., 2, 6 [66] 65).

${ }^{96}$ Wess. 455, 2. Conviene observar aqui que el paso a una tal reducción venía en cierta medida facilitado por otra referencia eulogiana al mismo mártir, y que viene justamente en la Epist. ad Wilesindum, en que se escribe: [...] Sanctio laycus de oppido Alauensi, Nonas Iunias, in hac ipsa aera [scil., octingentesima octuagesima nona] martyriali obitu triumphauit (ed. cit. de I. Gil, p. 503). En otras ediciones puede leerse Alhensi. (V. por ej., la de A. S. Ruiz: Obras completas de San Eulogio, Córdoba 1959, pp. 416-431).

${ }^{47}$ Las relaciones entre el reino de Asturias y el reino de Pamplona, en Estudios sobre la monarquia asturiana (1949), Oviedo 1971, pp. 223-243, concret. pp. 233s.

${ }^{9 x} O, c .$, p. 336.

* Recuérdese el caso - rigurosamente contemporáneo- de Musa Ibn Musa, el que, según la Crónica de Alfonso III (25, ed. de J. Gil, p. 144), "peleó contra los Francos y Galos e hizo muchos estragos y cautivos en su tierra (Multas ibi strages et predas fecit, según el texto latino)m, contándose justamente entre aquéllos Sancho Sánchez, duque de Vasconia, y su cuñado Emenón, conde del Périgord. Es verdad que C. Sánchez Albornoz (El tercer rey de España [1969], en Id.: Vascos y navarros..., pp. 252-255) aventuró la hipótesis sobre que la acción de que habla la Crónica pudiera ser la misma que la de la batalla de Abelda, de quien informan las fuentes musulmanas. Pero, aunque se demostrara la plausibilidad de tal hipótesis - empeño en el que no ayuda mucho el texto mismo de la Crónica, con ese adverbio ihi referido a Francos y Galos--, no dejaría de ser ésa una referencia válida para nosotros, ya que, fuese cual fuese el teatro de operaciones, estaria probado que Musa hizo múltiples prisioneros entre los Francos o Galos que combatió. 
ámbitos peninsulares bajo dominio franco ${ }^{\text {ton }}$, pudiendo en las mismas haber sido capturado ese joven originario de un oppidum galo. Y queda, luego, que en ese ámbito también se documentan - y con profusión-- los Sanchos ${ }^{101}$, ni deja, por otro lado, de haber localidades que pueden, por lo de la similitud fonética, competir con la alavesa en lo de reclamarse patrias del mártir cordobés, si bien puedan suscitarse dudas de si en rigor ${ }^{162}$ o en la intención de Eulogio ${ }^{103}$ formaban parte de la referida Gallia Comata : ahi está, de todos modos, Albi ${ }^{11+}$ - que no pilla tan a desmano de esa Gothia que mantiene en vilo Guillermo con la ayuda de los cordobeses. o de los ámbitos en que se mueven esos Sancho Sánchez y Emenón a los que combate Musa Ibn Musa ${ }^{105}$-; ahi, el Alba Helvia que documentan Plinio y otras referencias antiguas ${ }^{\text {tht }}$ en la Galia Narbonense, etc ${ }^{107}$. Pero diremos, en cualquier caso, por cerrar el tema, que, incluso para quienes entienden la Gallia Comata eulogiana como «la zona montañosa y cubierta de bosques que iba de Álava a Francia (Álava, Guipúzcoa y Baztán)», se habria tratado de «un término no indigena, sino más bien erudito, libresco, y no bien precisado» ${ }^{\text {Inx }}$, el que, por lo mismo, parece tener poco que decir en el asunto preciso que aqui nos ocupa.

\section{INDICIOS ONOMÁSTICOS QUE ABONARIAN EL SUPUESTO PSEUDO-FREDEGARIANO}

Son conocidos los pronunciamientos de M. Broëns sobre la relevancia del aporte franco al poblamiento de la Peninsula en la Tarda Antigüedad ${ }^{109}$, y los juicios - más bien negativos-- que

100 V. recogidas en el o. $c$. de C. Sánchez Albornoz (pp. $248 \mathrm{~s}$ ) algunas noticias sobre acciones en las que súbditos del califa cordobés intervienen militarmente contra los francos en la Marca Hispánica. Tales acciones, cuya noticia se debe al Kitab al-Muqtabis de Ibn Hayyan, tuvieron lugar por los años 846-849.

101 Ahi está ese Sanctius Sanctionis, de que habla el mismo Eulogio en la Epist. (cap. 1).

102 Pero ¿es que podia el mismo Eulogio en rigor hacer de la Baioaria una parte de la Gallia Togata (v. Epist. ad Wilies., 1), o de la Alba alavesa, un oppidum de la Comata?

${ }_{103}$ Obsérvese que Eulogio habla de la Gothia, término que a la sazón recubre, según todas las trazas a la antigua provincia Septimana de los Visigodos.

${ }_{104}$ Se documenta ciuitas Alhigensium (con var. Albiensium, entre otras) en la Not. prov. et civ. Galliae, que la incluye en la provincia Aquitanica I (Corpus Crhistianorum, t. 175: Itineraria et alia geogrphica. Turnhout 1965, I, p. 399); suena Alhiga en otros documentos tardoantiguos. Señalaremos aqui, a título de curiosidad, que en su traducción de la Epist. ad Wilies. A. S. Ruiz hace a Sancho «natural de la ciudad de Albi (Francia)» (O. c., p. 431), lo mismo que C. Fernández en el artículo que le dedica en el Dccionario de Historia Eclesiástica de España. (IV, Madrid 1975, p. 2173).

$105 \mathrm{~V}$. la referencia en la nota 99.

106 Nat. hist., 3, 36. Se documenta como civitas Albensium en la Not. prov. et civ. Galliae, o como civitas Albensis en Sid. Apolinar (v. referencias precisas s. v. Alba Helvorum en A. Pauly-G. Wissowa: Realencyclopädie der Klassischen Altertumswissenschaft, I' ${ }^{1}$, Stuttgart 1893, col. 1301).

${ }^{107}$ Otras posibles identificaciones (una más - Alba Augusta - en la Gallia Narbonensis), en A. Pauly-G. Wissowa: Ibid., cc. 1299-1303.

108 Asi, J. M. Lacarra: o. c., pp. 234s.

109 Los Francos en el poblamiento de la Peninsula Ibérica durante los siglos $17 y$ vil, en «Ampurias»" 17-18, 1955-1956, 59-77; v. también Id.: Le peuplement germanique de la Gaule entre la Méditerranée et l'océan, en "Annales de Midi» 68, 1956, 17-38, estudio que puede estimarse complementario del anterior, pero de cuyas conclusiones difiere un tanto. 
los mismos han merecido de la comunidad cientifica ${ }^{\prime \prime \prime}$. No vamos a ser nosotros, por supuesto, quienes rompamos una lanza por una teoria, algunos de cuyos supuestos - de indole tanto histórico-textual 11 " como lingüistica 112 - han sido invalidados de forma contundente por la critica de nuestros días. Ello no va a ser óbice, empero, para que de la masa de datos que acumula el autor en apoyo de su tesis tratemos, por nuestra parte, de recuperar aquéllos de índole lingüistica que, a nuestro modo de ver, no han hallado que sepamos respuesta suficiente por parte de sus contradictores, y pueden ser vistos como el indicio de la verdad relativa que pudiera esconder

110 V. como muestra, entre los lingüistas, J. M. Piel: Toponimia germánica, en Enciclopedia Lingüistica Hispánica. I, Madrid 1960, p. 536-38; entre los historiadores, J. Orlandis: Historia de España..., pp. 74-8 quien, al tratar del poblamiento germánico de la peninsula, no se acuerda para nada de los Francos, y se limita a consignar en la p. 87 que M. Broëns «pretendió demostrar la existencia de un poblamiento franco en Galicia en el siglo vin; mucho más explicito y rotundo M. Rouche: $L$ 'Aquitaine..., pp. 137-144 y 531 s, en quien se hallarán otras referencias.

ii Véase el partido que el autor saca de ciertas reelaboraciones más bien tardías de temas de historia franca: por ej., del Liber Historiae Francorum, relativo a Childeberto - un Childeberto que, para vengar a Clotilde, habría llegado hasta Toledo ni más ni menos, para de alli volver con su hermana cargado de tesoros (23, ed. de B. Krusch en MGH SRM, t. II, Hannover 1888, p. 279 [tema retomado casi tres siglos después por Aimoin de Fleuri: Historia Francorum, I. II, cc. VIII y XIX, ed. Migne: $P L$ 139, París 1853, cc. 669 y 688]; o del Tudis [...] Francorum reges infra Hispanias usque Minium superavit que se leía en una Chronologia et series regum gothorum del monasterio de Moissac (v. M. Bouquet: Recueil des historiens des Gaules et de la France, tt. 1-8, Paris 1738-1752, II, p. 705), pasaje que, según hizo ver en su dia M. Risco (La Vasconia..., pp. 328s), deriva de una alteración del Teudis [...] Francorum reges infra Spanias usque nimium superabit del Ordo gentis Gotorum del Cronicón Albeldense (ed. de J. Gil, p. 166). Temas, pues, que se dirian ya obviados por la crítica más alertada...

112 No se acepta, en concreto, que las formaciones toponimicas en -ingos, -engos (las en -ens, -enx del área aquitana y en menor grado de la septimana) haya que relacionar con episodios de poblamiento franco, sino más bien godo, volviendo en este punto a las tesis de W. von Wartburg y de E. Gamillsecheg (v. M. Rouche: L'Aquitaine..., pp. 137s). Tampoco resulta tan claro -o se postulan investigaciones más ceñidas en cada área individualizada para verificarlo - que las formaciones toponimicas tipo Thionville o Berantevilla - antropónimo seguido de villa - sean indicativas de implantación franca. No faltan, de hecho, autores que estiman plausible su origen a partir de un poblamiento de habla romance, y esto incluso en el caso de tratarse de antropónimos de origen germánico. Se señala en tal sentido: 1) que la moda del nombre germánico fue un hecho entre tales poblaciones a partir de cierto tiempo; y 2) que éstas tampoco desconocian en su más o menos inmediato pasado formaciones del tipo de Augustodunum o Caesaromagus (v. F. Lot: De l'origine et de la signification historique et linguistique des noms de lieux en ville et en court, en «Romania», n. 234, abril 1933, t. 59, pp. 199-246; J. Johnson: Étude sur les noms de lieux dans lesquels entrent en composition les éléments court, ville et villiers, París 1946) - ejemplos de formaciones onomásticas antiguas, que cabría incrementar con el de Flaviobriga, entre los referidos al área cicumpirenaica, o con los de origen euskérico altomedieval tipo Obécuri. Herramélluri, etc.- Son de citar también en este punto M. Roblin (Le terroir de Paris aux époques gallo-romaine et franque, París 1971), quien, a falta de elementos de juicio más decisivos, estimaba oportuno suspender el juicio (v. Ibid., concret. p. 90), y M. Rouche, a quien un análisis pormenorizado del caso aquitano permite ser más afirmativo en cuanto al origen franco de tales formaciones en -villa (o. c., pp. 142144). En fin los autores están muy lejos de pensar, al igual que M. Broëns, que «la mayor parte» - «si no todos»- de los topónimos que suenan como Franco, Francos, Francelos, etc. remitan por necesidad al étnico Francos (v. J. M. Piel: o. c., p. 537), o que daten «por lo menos» de fines del siglo vi (Los Francos..., p. 65), refiriéndolos por lo común, bien al contrario, a tiempos bien avanzados de la Edad Media, cuando la corriente repobladora de origen foráneo se hace sentir en torno de la ruta jacobea o en las empresas de reconquista de diversas zonas de la península (v. M. Rouche: L'Aquitaine..., pp. 531s, nota 7). 
la noticia pseudo-fredegariana sobre el dux Francio de Cantabria. A ellos añadiremos las referencias de índole onomástica $o$, más globalmente, lingüistica que nos ha deparado el azar de nuestras rebuscas en los textos altomedievales, referencias que, a nuestro modo de ver, han de ser explicadas asimismo en relación con hechos pobladores anteriores al cambio del milenio.

No hace a nuestro caso extendernos aqui sobre el lote de topónimos con el tema Francos o Francelos, que documenta $\mathrm{M}$. Broëns para el primer milenio en relación con el área gallega - en concreto, dos tardoantiguos, y anteriores cuando menos al siglo $\mathrm{x}$ otros dos más- ${ }^{113}$. Digamos, para abreviar, sobre los primeros - documentados en el famoso Parroquial Suevo del siglo $\mathrm{vi}^{114}$ - que pueden muy bien ser explicados en relación con el régimen de contactos bastante intensos, que, por las trazas, mantiene a la sazón el reino suevo con los Merovingios por vía maritima ${ }^{115} ; \mathrm{y}$, en cuanto a los otros, que el primero de ellos deriva, por lo que parece, de una falsificación de fines del siglo xı o XII (y decimos parece, porque Broëns no aduce otros datos individualizadores del documento, que el de la presencia del topónimo castrum de Fran$c o s$ en el mismo, más la fecha de su expedición en el 841 , datos que se repiten à peu près en un conocido falso de la colección diplomática astur $\left.{ }^{116}\right)$, mientras que del segundo sólo sabemos, por lo que explicita el mismo M. Broëns, hallarse asociado a una villa en un documento datado en el 877 , y parecerle, por otro lado, al autor "distinto del primero» "117.

Tampoco vamos a demorarnos aquí en la consideración de los indicios onomásticos de supuesta implantación franca, que documenta A. Prieto Prieto para el solar astur en la primera mitad del siglo x y comenzado el segundo milenio ${ }^{118}$, ya que, de suponérseles a los topónimos en cuestión un arranque temporal anterior al siglo vil, podrían en principio ser explicados en razón de los contactos que por vía marítima mantenía, al parecer, el litoral astur-galaico con el mundo franco en el siglo $\mathrm{vI}^{119}, \mathrm{y}$, caso de retrasarse algo ese arranque temporal -opinión a que se inclina a la postre el autor-, nos remitirian a un horizonte histórico - el de las relaciones que mantuvo Alfonso II el Casto con Carlomagno a fines del siglo vill- que se saldría del marco estrecho que aquí nos hemos impuesto.

Ahora bien, lo que por nuestra parte podemos añadir es que el étnico Francos se documenta también, con anterioridad al cambio de milenio o antes al menos del auge de las peregrinaciones jacobeas, asociado a entornos más próximos al supuesto ducado franco de Cantabria, y más próximos también a los enclaves en que se registran los importantes hallazgos arqueológi-

113 O. c., p. 65.

114 Sobre el documento, v. P. David: Études historiques sur la Galice et le Portugal du VI au XIF siècle, Lisboa-París 1947, pp. 1-82 ( «L'organisation ecclésiastique du royaume suève au temps de Saint Martín de Braga»). Sobre los topónimos en él atestiguados, Ibid., pp. 75ss; A. de Sousa: Topónimos do Paroquial Suevo (séc. VI), wn «Botet. Mensal Soc. Lingua Port.» 13, 1962, 350-365; 14, 1963, 7-17.

115 V. referencias de las nn. 40-42. A señalar, en todo caso, las reservas que al respecto expresa J. M. Piel: o. c., pp. 536-538.

${ }^{116}$ Cfr. A. C. Floriano: Diplomática española del periodo astur. Estudio de las fuentes documentales del reino de Asturias (718-910). I: Cartulario critico. Primera Parte (Desde Pelayo a Orodoño I), Oviedo 1949, p. 208 (un documento de donación datado el 8 de enero de 841 , en que se habla de un monasterio situado «iuxta Castrum uocitatum Francos»). Pero, como dicho, se trata de un falso, relacionado con otros dos falsos más (Ibid., pp. 53s, 189-192 y 210s).

117 O. c., p. 65.

118 ¿Establecimientos francos en el reino de Asturias? Sus posibles ecos: toponimia y epopeya, en «Asturiensia medievalia» 4, Oviedo 1981, pp. 61-85.

$119 \mathrm{~V}$. las referencias de las $\mathrm{nn} .40-42$. 
cos a que haciamos referencia al inicio de este trabajo. En el Cartulario de S. Millán y en un diploma que se data en el 952 se hace alusión a un rivo de Francos ${ }^{121}$ en un contexto ( $;$ actual Rufrancos, en el partido judicial de Villarcayo?) que se diria no muy alejado de la vaga Cantabria de ciertos textos tardoantiguos o del en otro lugar mentado yacimiento de Nanclares de Gamboa ${ }^{22}$. En el mismo Cartulario, y en el célebre diploma conocido como la "Reja de San Millán», datado en el 1025, vuelve a aparecer por dos veces la forma Prango como nombre de dos comunidades alavesas de la hermandad del rio Ayuda, que pagaban reja al famoso monasterio riojano ${ }^{122}$. En fin, para el año 1074 documenta M. Broëns un Rivo Francorum que refiere al partido judicial de Lerma (Burgos) ${ }^{123}$, sin que, empero, explicite la procedencia ni otros pormenores de tal atestación toponimica ${ }^{124}$.

Y surge naturalmente la pregunta sobre el arranque temporal de los episodios pobladores que subyacen al nacimiento de tales topónimos. Señalaremos al lector que por precaución hemos prescindido voluntariamente del tercero de ellos, ya que, si la toponimia recogida en un documento deriva por lo común de situaciones anteriores, lo avanzado del siglo xı en este caso aconseja alguna reserva sobre que pueda estimárselo reflejo de hechos pobladores antiguos. En cuanto a los otros dos, parece indudable en el primer caso y altamente probable en el segundo, que nos las habemos con hechos de población anteriores a los que tienen lugar en el área en relación con la peregrinación jacobea, la que, si se documenta en casos muy singulares para antes del final del primer milenio ${ }^{125}$, no parece cobrar relevancia poblacional en ella hasta bien entrado el siglo $\mathrm{xl}^{126}$. Ahora bien y admitido eso, ¿habrá que referirlos, como lo

120 Cartulario de San Millán, 64 (ed. de A. Ubieto Arteta, pp. 75s).

121 Las menciones toponímicas que, por lo demás, recurren en el diploma todas hacen referencia a lugares de Castilla próximas a Valdegobia, o a localidades de Álava y Guipúcoa, en torno de Urbina y Ullibarri, lugares éstos que son mencionados también.

122 Cartulario de San Millán, 180 (ed. de A. Ubieto Arteta,. p. 178). Las localidades vuelven a aparecer en un documento de 1257 como Franco de Suso y Franco de Yuso (v. A. Ubieto Arteta: Un mapa de la diócesis de Calahorra en 1257, en «Revista de Archivos, Bibliotecas y Museos» 60, 1954, 374-394, aquí en part. p. 389), fundiéndose con posterioridad en el único Franco que se documenta desde la segunda mitad del siglo xvı y corresponde al actual del condado de Treviño. Dejando de lado otros problemas (v. en sentido J. M. Piel: Toponimia germánica..., p. 537; F. Marsa: Toponimia de reconquista, en Enciclopedia Lingüistica Hispánica, I, Madrid 1960, pp. 641s), pensamos que la mutación Franco $>$ Prango pudo haberse debido a los hábitos fonéticos de una comunidad euskaldum, a la que no resultan extraños en los préstamos de otras lenguas esos cambios de $f$ inicial en $p$ (v. fagus $\rightarrow$ pago, ficus $\rightarrow$ piko o fraile $\rightarrow$ praile). Sobre el topónimo, v. las referencias que recoge M. N. Sánchez González Herrero: El habla y la toponimia de La Puebla de Arganzón y el Condado de Treviño, VitoriaGasteiz [1986], pp. 186s.

${ }^{123}$ O. c., p. 75.

124 En el «Índice de lugares» que hace figurar J. del Álamo al final de su Colección diplomática de San Salvador de Oña (2 vv., Madrid 1950) y concretamente en la p. 1002, hay una entrada que sueña Francorum (rio), pero a la que, por olvido o por lo que sea, no se la asigna referencia de pág. Lamentamos que nuestros esfuerzos por localizar el topónimo en las cerca de mil páginas de texto que incluye la colección hayan resultado baldíos... Pero acaso no esté de más la pregunta de si este río Francorum podría corresponder al Rivo Francorum de M. Broëns, que pervive en el actual Ríofranco.

$125 \mathrm{~V}$. el caso del obispo aquitano Gotescalco en J. Cantera: Un ilustre peregrino francés en Albelda (Logroño) (Años 950-951), en «Berceo» 3, 1948, 427-42; 4, 1949, 107-121, 299-304, 329-340.

${ }_{126}$ Cfr. J. M. Lacarra: La repoblación de las ciudades en el camino de Santiago: su trascendencia social, cultural y económica, en L. Vázquez de Parga, J. M. Lacarra, J. Uria Riu: Las peregrinaciones a Santiago de Compostela, t. I, Madrid 1948, pp. 465-497. 
hace A. Prieto para el caso astur, a contingentes de soldados carolingios destacados en la zona, a los que, en virtud de un supuesto acuerdo de Alfonso II con la corte de Aquisgrán, se les habría asignado un servicio de anubda o de vigilancia en las fronteras de Álava y al-Qilè? Hemos de decir que nada tenemos en principio contra la hipótesis en si o la forma en que la instrumenta el referido autor, sino que la zona alavesa o castellana en que se documentan esos topónimos, aunque dependiente teóricamente de la órbita astur y más o menos accesible a posibles misiones francas a despecho de la perfidia vascona, se revela, en todo caso, más recalcitrante frente a la corte ovetense ${ }^{127}$ que la zona astur montañosa en que documenta A. Prieto sus Francos y guardiatores, y que nada hay, por lo demás, de positivamente documentado que privilegie esa solución sobre otras que puedan razonablemente argüirse.

Entre los indicios onomásticos de implantación franca que suelen comúnmente aducirse tenemos, luego, las formaciones toponímicas en -villa. En otro lugar ${ }^{12 x}$ dejamos dicho algo ya sobre la problemática que se suscita en torno a las mismas, y no es cuestión de que ahora reincidamos en el tema. Interesa, empero, señalar que entre los que cita como casos expresivos M. Broëns los más se documentan justamente en el área ${ }^{129}$, en la que, por otro lado, nos ha sido posible localizar alguna más. Una que ha merecido de manera particular la atención del investigador francés es Berantevilla, formación onomástica atestiguada como Verantivilla ya desde 1080 en el Cartulario de San Millán ${ }^{130}$, y en la que Broëns se atreve a reconocer la presencia del nombre de Barontus - uno de los duces que, según el Cronicón de Fredegario, acompañaron a Dagoberto en su expedición del 645 contra los Vascones ${ }^{131}$-. En la jurisdicción de la actual Berantevilla encontramos, por otro lado, Lacervilla ${ }^{132}$, que en 1257 se documenta Licerivilla. Sin salirnos aún de Álava y en un contexto próximo, tenemos: Elhenivilla, documentada en 1025 en la zona de Nanclares ${ }^{133}$; Uxeminivilla, en el arciprestazgo de La Ribera, que se registra en un texto de $1257^{134} ;$ Nubilla, en el mismo arciprestazgo, documentada como Lunivilla en $1025^{135}$ y Nuevevilla años después ${ }^{136}$; Reinavilla, en la zona de Laguardia, que en 1366 se registra como aldea arruinada ${ }^{137}$. En fin, hay un barrio de nombre Garavilla en Llanteno

127 V. la Crónica de Alfonso III, 16, 19, 23; Crónica de Albelda, XV, 12 (numeración de ambas, según la edición de J. Gil Fernández: Crónicas asturianas..., Oviedo 1985).

$128 \mathrm{~V}$. las referencias de la nota 112.

${ }^{129}$ O. c., pp. 70 s.

${ }^{130}$ Cfr. L. Serrano: Cartulario de San Millán de la Cogolla, Madrid 1930, p. A señalar que un documento calagurritano de 1257 menciona dos Verantevillas. una, en el acredianato de Álava y arciprestazgo de Treviño, y otra en el arcedianato de Nájera y arciprestazgo de Miranda (v. A. Ubieto Arteta: Un mapa de la diócesis de Calahorra en 1257, en «Revista de Archivos, Bibliotecas y Museos» $60,1954,374-394$, aqui en part. pp. 389 y 392, respectivamente).

131 Chron., IV, 78 (ed. de B. Krusch, pp. 159-161).

132 Cfr. A. Ubieto Arteta: Un mapa..., p. 390).

133 Cfr. Cartulario de San Millán, 180 (ed. de A. Ubieto Arteta, p. 177).

${ }^{134}$ Cfr. A. Ubieto Arteta: Un mapa..., p. 389. Algunos leen Unxenevilla (v. G. López de Guereñu: Toponimia alavesa seguido de Mortuorios o despoblados y Puevos Alaveses, Bilbao 1989, p. 586).

${ }_{135}$ Cfr. Cartulario de San Millán, 180 (ed. de A. Ubieto Arteta, p. 178) (se la incluye en el «Alfoz de Fornello", concretamente).

${ }^{136}$ Cfr. A. Ubieto Arteta: Un mapa..., p. 389.

137 Cfr. G. López de Guereñu: Toponimia alavesa..., pp. 572 y 649. 
(valle de Ayala, Álava), y nombres de heredades o labrantios dichos Birihila ${ }^{13 x}$ en Marquinez, Lagrán y Artaza de Foronda ${ }^{130}$, nombres de los que, empero, no hemos hallado acreditaciones antiguas significativas. En la actual Navarra, y lindando por el Oeste con la zona que registra las más de las atestaciones toponimicas anteriores, tenemos Genevilla, que suena Uxanavilla en el citado documento de $1257^{140}$. En la provincia de Burgos, pero en un contexto más bien próximo al que definen las citadas formaciones onomásticas, registra M. Broëns Movilla, en Salas de Bureba, y una nueva Elhenivilla, en Sedano, de la que afirma hallarse acreditada en el Cartulario de San Millán para el siglo $\mathrm{xI}^{1+1}$. $\mathrm{Y}$ a esto se reduce el material onomástico con terminación en -villa que hemos podido documentar en el área, si dejamos de lado el que el autor citado registra para Zaragoza y Huesca ${ }^{1+2}$, para el que, empero y caso de revelarse de origen germánico, cabría quizá hallar una explicación mejor, a nuestra manera de ver, en el contexto de la colonización carolingia de los altos valles pirenaicos.

Asi las cosas, y entretanto los lingüistas no se pronuncien sobre la composición de tales formaciones onomásticas - distinguiendo las que reúnen los elementos característicos de las formaciones germánicas (antropónimo y terminación en villa), y las que no (formaciones a partir de un nombre común y terminación en villa) - al historiador sólo le resta destacar quizá la forma llamativa en que las mismas se centran y/o densifican en un área cercana a la vaga Cantabria de ciertos textos tardoantiguos y altomedievales o a los yacimientos de Aldaieta y Buzaga. ¿Mero azar, sin ulterior trascendencia? Uno puede responder que en un caso análogo de concentración de formaciones toponimicas en villa justo en la periferia exterior de la provincia septimana - punto crucial en la frontera entre el reino godo y el franco en los siglos VI-VII - un moderno autor, y tras un meticuloso análisis de todo el material, se ha sentido autorizado a interpretarlas como el síntoma de una consistente implantación franca, que habria tenido como objetivo el reforzamiento del dispositivo fronterizo por ese lado ${ }^{143}$. ¿No podrían serlo también en cierta medida en el caso que nos ocupa?

Vamos a cerrar nuestra recogida de los materiales onomásticos indiciarios de implantación franca, sometiendo a la consideración de los lingüistas una formación de otro tipo, pero que suele relacionarse también con aquélla ${ }^{144}$. Se trataría - si no van del todo descaminadas nuestras apreciaciones- de una formación con desinencia en curtis, única con la que hemos topado hasta ahora. En el texto de referencia, datado en 1257, se registra como Elegortes, en el arciprestazgo de Viana en Navarra, y parece responder hoy a un despoblado llamado Elgortes,

${ }_{138}$ M. Broëns escribe significativamente Virivilla, refiriendo el término a Lagrán, Laguardia $(o . c$, p. 77); pero no aporta testimonio alguno que privilegie una tal grafía sobre la de Biribila (v. nota siguiente), en cuyo favor podría quizá argüirse, tratándose de labrantíos o heredades, el euskérico biribil (redondo), al que seguiría en este supuesto el determinante $a$.

139 Cfr. G. López de Guereñu: Toponimia alavesa..., p. 123.

140 Cfr. A. Ubieto Arteta: Un mapa..., p. 394 (en el «arciprestazgo de Bernedo»). En la zona de Tudela (Nav.) y en el siglo xıII registra M. Broëns un Ardevillas (o.c., p. 77), al que, empero, se nos hace muy difícil reconocer, habida cuenta de la peculiar historia que atraviesa esa zona en los siglos tardoantiguos y altomedievales, como reflejo onomástico de un episodio de implantación franca prejacobea.

141 O. c., p. 77.

142 O. c., p. 77.

$143 \mathrm{Cfr}$. M. Rouche: L'Aquitaine..., pp. 143s.

144 V. en la n. 112 referencias a los trabajos de F. Lot y J. Johnson. 
cerca de Torralba ${ }^{145}$. Presentamos este nuevo dato con todas las reservas que se merece el juicio de uno que por desgracia no puede presumir de hallarse medianamente versado en temas de Lingüistica; pero, caso de revelarse acertada nuestra apreciación, significaria un indicio más entre los que avalarian la especie pseudo-fredegariana de un dominio franco al Sur de la cadena pirenaica. ¿Se ha parado mientes, a todo esto, en que, justo al ladito del yacimiento de Aldaieta en Nanclares de Gamboa, se documenta ya en 1025 un topónimo que suena Hurizahar, es decir, villa o poblado viejo ${ }^{146}$ ?

\section{EPÍLOGO SOBRE LAS FUNCIONES Y LA PERCEPCIÓN SOCIAL DE LA FRONTERA EN LAS SOCIEDADES ANTIGUAS}

Se trata, sin duda, de un tema de enorme complejidad, cuyo tratamiento adecuado exigiría un generoso esfuerzo interdisciplinar, inspirado en los métodos y prácticas de los antropólogos culturales. Aqui, por supuesto, no vamos a embarcarnos en una tal aventura, y nuestro objeto se limitará a llamar la atención sobre la complejidad del tema mediante unas cuantas reflexiones deslavazadas.

Éstas nacen de nuestra sospecha - no sé si suficientemente fundada- de que, al tratar de cuestiones de límites entre naciones y formaciones politicas antiguas, atribuimos a menudo anacrónicamente a éstas formas de percepción de las fronteras y de delimitación de las mismas, que sólo se dirian documentarse en tiempos posteriores, como resultado de complejos procesos sociales y políticos y cuando los aparatos de poder respectivos cuentan con los recursos materiales y humanos suficientes para hacer efectivo hasta ese nivel el control del territorio percibido como propio. No queremos decir, al hablar asi, que en las sociedades antiguas se ignoren las formas de control más riguroso, sobre todo cuando se trata de fijar los limites de los predios privados. Lo que queremos poner de relieve es que, cuando como delimitadores entre pueblos o formaciones políticas se citan y operan magnitudes como la del complejo pirenaico - en el caso de Galia e Hispania, del reino visigodo y el mundo merovingio, etc.-, en tales casos el límite o frontera ha de ser por necesidad percibido como algo por demás vago y difuso, máxime si, como en el caso del área que nos ocupa, la cadena pirenaica se diría prolongarse a una simple mirada en el laberinto de montes que constituyen la Depresión Vasca ${ }^{147}$. Para hacer aún más inevitable esa impresión, contará el que durante siglos ese entorno constituya como el epicentro de la resistencia vascona frente a los intentos asimilistas que protagonizan las grandes formaciones politicas del norte y del sur, y, por lo mismo, como el punto en el que se revelarán menos eficaces los dispositivos de control de los aparatos de poder respectivos. ¿Puede extrañar, así, la impresión de enorme vaguedad en lo geográfico, que se desprende a menudo de las fuentes de la época cuando se refieren a hechos que tienen que ver con estos aledaños ${ }^{148}$ ? Y

145 Cfr. A. Ubieto Arteta: Un mapa..., p. 391.

146 Cfr. Cartulario de San Millán, 180 (ed. de A. Ubieto Arteta, p. 176). En 1257 se escribe Uriçahar (v. A. Ubieto Arteta: Un mapa..., p. 387).

${ }_{147}$ V. por ej., Pomponio Mela 2, 6 (85), Floro 2, 33, 46 y Orosio 6, 21, 2, pasajes que, a nuestro entender, reflejan con bastante claridad esa idea que se hacian los antiguos sobre la prolongación del Pirineo en los montes vascos y en el sistema cantábrico. V., empero Plinio: Nat. hist., 3, 30 o Ptolomeo: Greogr., 2, 7, 4 (5).

${ }_{148}$ V. en este punto P. J. Camena D'Almeida: Les Pyrénées: développement de la connaissance géographique de la chaîne, París [1983]; A. Garcia y Bellido: Los Pirineos a través de los geógrafos griegos y romanos, en «Pirineos» 8, 1952, 471-484; J. Bosch Vila: Los Pirineos según los principales autores árabes de la Edad Media, en «Pirineos» 5, 1949, 173-218; en fin, J. Caro Baroja: Sobre el 
dicho sea esto incluso dejando de lado las delirantes "definiciones» de Guasconia y de Spanoguasconia, que resultan del texto del Ravenate ${ }^{1+9}$, en el que, como se sabe, el área de influencia vascónica aparece extrañamente sobredimensionada. Pero ¿,cómo no traer, en todo caso, a colación aqui, aunque remitan a tiempos un tanto posteriores, las referencias documentales recogidas por J. Caro Baroja, en que se muestra a las claras que para los moradores de los valles altoaragoneses, por ej., el término Yspania o Hispania venía a significar allá por el cambio del milenio la parte llana que se extendia al Sur del Pirineo y del Prepirineo ${ }^{150}$ ?

Tras de lo cual voy a permitirme unas últimas preguntas ¿Cabe pensar sinceramente que fuera operativa durante los siglos VI-VII, ni tan siquiera en el plano de las representaciones mentales - es decir, en ese nivel en que se realimentan y cobran nueva urgencia los sueños imperiales o las nostalgias irredentistas de los pueblos ${ }^{151}$-, una linea fronteriza entre la Galia merovingia y la Hispania goda, como la que, sobre la base de la divisoria de aguas Norte-Sur poco más o menos y no sin algunos conflictos, ha ido definiéndose y elevándose a letra acordada en los tiempos modernos? ¿Hasta qué punto pudo ver herido su orgullo patrio un visigodo por el hecho de que se dieran enclaves bajo dominio merovingio - más menos nominal, más o menos efectivo- a la altura de Villarreal de Álava, o de Idocin en el valle de Elorz (Navarra)? ¿En fin, resultaria tan extraño que en esa zona de dominio incierto, que constituye el ámbito vascón al Norte de la línea defensiva Amaya, Victoriacum, Ologicus o Pompaelo, se dieran enclaves enfeudados en mayor o menor medida al poder merovingio, sobre todo si - en la linea de lo que revela un primer ensayo interpretativo de los hallazgos de Aldaieta, Buzaga y Pamplona- el elemento humano y cultural dominante en tales enclaves hubiera que referirlo no tanto a lo franco en sentido estricto, cuanto a lo aquitano-novempopulano, es decir, a un ámbito que desde el lado franco es percibido cada día más como formando un bloque con la Vasconia perjura y rebelde ${ }^{152}$ ? Porque no convendría olvidar en este punto que ese mundo constituía en todo caso para el vascón cispirenaico (por razones de vecindad y de remotos parentescos presumiblemente, sobre las que algo dejan entrever los autores clásicos ${ }^{153}$, pero de las que no puede ser cuestión ahora ${ }^{154}$ ), un horizonte referencial en cierto modo próximo y, en cualquier caso, no tan extraño como el franco o el godo, a despecho de las relaciones de subordinación jerárquica - más o menos real, más o menos teórica- que pudieran haber vinculado a tales enclaves o a los jefes que los mandaban con los monarcas merovingios.

mundo ibérico-pirenaico, San Sebastián 1988, pp. 67-76 y 94s, quien se explaya en atinadas observaciones sobre el "cierre de horizontes» que se produce desde la Antigüedad Tardia sobre el mundo pirenaico, cierre de horizontes que se habria traducido en un empobrecimiento o en una esquematización de los conocimientos relativos a las particularidades de la cadena y de las gentes que la poblaban.

149 Cfr. Ravennatis anonymi Cosmographia, I, 3; IV, 40-42 y 45s; V, 28.

150 O. c., pp. 76 y $94 \mathrm{~s}$.

151 Cfr., de todas formas, en este punto J. J. Sayas Abengoechea: La búsqueda visigoda de la unidad territorial y el caso vascónico, en "Veleia» 5, 1988, 189-206.

152 Apuntaba ya en este sentido, al tratar del entronque cultural de ciertos materiales hallados en el así llamado «cementerio visigodo de Pamplona», Ed. James: Septimania and its Frontier: An Archaeological Approach, en Ed. James (ed.): Wisigothic Spain. New Approaches, Oxford 1980, pp. 223-241, partic. 227 s. V., por otro lado, en ese sentido las múltiples referencias que recojo en la obra cit. en la n. 7.

${ }_{153}$ V., por ej., César: De bel. gal., 1, 1, 1-7 relacionándolo con 3, 23, 3-6; asimismo Estrabon 4, 1, 1 y $4,2,1$.

154 Puede verse, en cualquier caso, J. Caro Baroja: La Aquitania y los Nueve Pueblos, en "AEA» 17, 1944, 113-134; Id.: Sobre los pueblos de Aquitania y su relación con los vascos, en Historia general del Pais Vasco, v. II [:Edad Antigua], San Sebastián 1980, pp. 261-386. 